\title{
Der Einfluss der Abgeltungssteuer auf die Haltedauer von Aktien - eine empirische Untersuchung von Directors' Dealings am deutschen Kapitalmarkt
}

\author{
Rainer Niemann • Silke Rünger
}

Eingegangen: 22. Oktober 2014 / Angenommen: 3. Oktober 2016 / Online publiziert: 23. November 2016 (C) Der/die Autor(en) 2016. Dieser Artikel ist eine Open-Access-Publikation.

Zusammenfassung Durch die Offenlegungspflichten von Directors' Dealings (Insidergeschäften) von deutschen börsennotierten Kapitalgesellschaften können wir individuelle Haltedauern von Aktien ermitteln und empirisch analysieren. Da Gewinne aus privaten Aktienverkäufen unter dem Halbeinkünfteverfahren erst nach Ablauf der einjährigen Spekulationsfrist steuerfrei vereinnahmt werden konnten, entstand ein Lock-in-Effekt. Mit der Einführung der Abgeltungssteuer entfällt dieser Anreiz, da Gewinne aus privaten Aktienverkäufen unabhängig von der Haltedauer besteuert werden. Basierend auf einer Stichprobe von 1211 Insidergeschäften (922 davon aus dem Halbeinkünfteverfahren und 289 aus der Abgeltungssteuer) zeigen wir, dass die Haltedauer für Gewinngeschäfte unter der Abgeltungssteuer wie erwartet signifikant niedriger ausfällt. Im Gegensatz dazu weisen Verlustgeschäfte unter der Abgeltungssteuer ebenfalls eine niedrigere Haltedauer auf, weshalb eine steuerlich motivierte Wahl des Veräußerungszeitpunktes für Verlustgeschäfte nicht plausibel erscheint.

Schlüsselwörter Directors' Dealings · Abgeltungssteuer · Haltedauer · Lock-inEffekt

JEL-Classification $\mathrm{G} 11 \cdot \mathrm{G} 14 \cdot \mathrm{H} 24 \cdot \mathrm{H} 31$

Die Autoren danken Martin Fochmann, den Teilnehmern des Workshops „Empirische Forschung in der Betriebswirtschaftlichen Steuerlehre“ 2012 in Mannheim sowie zwei anonymen Gutachtern für wertvolle kritische Hinweise.

R. Niemann $(\bowtie) \cdot$ S. Rünger

Institut für Unternehmensrechnung und Steuerlehre, Karl-Franzens-Universität Graz, Universitätsstraße 15/G2, $8010 \mathrm{Graz}$, Österreich

E-Mail: niemann@uni-graz.at

S. Rünger

E-Mail: silke.ruenger@uni-graz.at 


\title{
The Impact of the Introduction of a Final Withholding Tax on Holding Periods of Share Investments - an Empirical Investigation of Directors' Dealings in Germany
}

\begin{abstract}
Directors of German public firms are required to notify the company and the public of their own dealings involving shares of the company. We make use of this publicly available information to calculate and analyze holding periods for share investments of directors. Prior to 2009, capital gains resulting from private share investments were tax-exempt after a holding period of one year, causing a lock-in-effect. Starting in 2009, a final withholding tax on all individual capital gains, regardless of the holding period, was introduced. We analyze 1,211 directors' dealings (922 prior to and 289 after the introduction of the final withholding tax) and are able to show that the introduction of the final withholding tax significantly decreases holding periods if the investment resulted in a capital gain. Contrary to our expectations, also the holding period of investments resulting in capital losses has significantly decreased, showing no indication for a tax-induced loss selling.
\end{abstract}

Keywords Directors' dealings $\cdot$ Final withholding tax $\cdot$ Holding period $\cdot$ Lock-in effect

\section{Einleitung}

Steuerliche Primärdaten in Zusammenhang mit Aktienkäufen und -verkäufen am deutschen Kapitalmarkt, insbesondere Haltedauern, konnten in der empirischen Betriebswirtschaftlichen Steuerlehre mangels Verfügbarkeit bisher nicht ausgewertet werden. Durch die Offenlegungspflichten von Directors' Dealings (Insidergeschäften) in Zusammenhang mit dem Handel von Aktien von deutschen börsennotierten Kapitalgesellschaften wird der Steuerforschung eine neuartige Datenquelle erschlossen, mit der erstmals individuelle Haltedauern von Aktien ermittelt werden und ein eventueller Steuereinfluss auf Haltedauern empirisch analysiert werden kann. Mit den bislang zur Verfügung stehenden Datenquellen wie zB amtlichen Steuerstatistiken ist eine Analyse individueller Anlageentscheidungen dagegen nicht möglich.

Die deutsche Steuerreform 2009 bewirkte mit der Einführung der Abgeltungssteuer eine erhebliche Ausweitung der Besteuerung privater Veräußerungsgewinne aus Aktiengeschäften. Bis Ende 2008 waren Veräußerungsgewinne nur innerhalb der Spekulationsfrist von einem Jahr oder bei Vorliegen einer wesentlichen Beteiligung steuerpflichtig. Seit dem 01.01.2009 werden Veräußerungsgewinne hingegen stets mit dem Abgeltungssteuersatz von $25 \%$ (zuzüglich Solidaritätszuschlag) belastet. Ein Anreiz zum Abwarten der Spekulationsfrist zur steuerfreien Realisierung des Veräußerungsgewinns ist somit für seit 2009 erworbene Wertpapiere nicht mehr gegeben. Unter der Annahme, dass Wertsteigerungen vorliegen, ist demnach eine Reduktion der Haltedauern von privaten Investoren zu erwarten. Während in der US-amerikanischen Literatur der Lock-in-Effekt der Veräußerungsgewinnbesteuerung regelmäßig und der Einfluss der Besteuerung auf die Haltedauern von Aktien 
vereinzelt analysiert wurden, ${ }^{1}$ existiert bislang keine deutsche Untersuchung über den Einfluss der Abschaffung der Spekulationsfrist bzw Einführung der Abgeltungssteuer auf Haltedauern. Es ist daher unbekannt, inwieweit inländische private Investoren auf die Abschaffung der Spekulationsfrist reagiert haben. Die vorliegende Studie soll diese Forschungslücke schließen und einen Beitrag zur Analyse des Steuereinflusses auf private Veräußerungsgeschäfte leisten.

Dazu analysieren wir 5650 Insidermeldungen und identifizieren daraus 1211 Insidergeschäfte (dh Käufe und zuordenbare Verkäufe), von denen rund $76 \%$ im alten Steuersystem stattgefunden haben. Ein Vergleich der Haltedauern zeigt, dass diese seit Einführung der Abgeltungssteuer im Durchschnitt um rund 380 Tage, dh um mehr als ein Jahr kürzer sind und dieser deutliche Unterschied auch statistisch signifikant ist. Diese Beobachtungen unterstützen die Hypothese, dass Insider am deutschen Kapitalmarkt auf die Abgeltungssteuer mit kürzeren Haltedauern reagiert haben, sofern sie grundsätzlich handelsaktiv und nicht per se langfristig orientiert sind.

Dieses Ergebnis ist auch unter Corporate-Governance-Aspekten relevant. Unter der Annahme, dass eine Interessenharmonisierung von Anteilseignern und Management durch eine möglichst langfristige Beteiligung des Managements am Aktienkapital der Unternehmung herbeigeführt wird, erschwert eine Veräußerungsgewinnbesteuerung, die zur Verkürzung von Haltedauern führt, eine anreizkompatible Entlohnung. Eine Verkürzung der Haltedauern muss jedoch nicht notwendigerweise zu einer reduzierten Beteiligung des Managements am Aktienkapital führen, sondern könnte durch eine erhöhte Handelsaktivität kompensiert werden. Unmittelbar nach Einführung der Abgeltungssteuer liegen aber keine erhöhte Transaktionshäufigkeit und kein erhöhtes Transaktionsvolumen vor. Ein Einfluss der Steuerreform auf die Insiderhandelsaktivität kann daher nicht gezeigt werden.

Steuerplanungsaktivitäten in Zusammenhang mit dem Realisationszeitpunkt von Veräußerungsverlusten können nicht nachgewiesen werden, da die durchschnittliche Haltedauer bei Verlustgeschäften unter der Abgeltungssteuer ebenfalls sinkt.

Die Verkürzung der Haltedauer von handelsaktiven Insidern durch die Einführung der Abgeltungssteuer bildet das zentrale Ergebnis unserer Studie und kann mit Hilfe von linearen Regressionen und Verweildauermodellen gezeigt werden. Alternative Spezifikationen von Verweildauermodellen liefern jedoch auch Indizien dafür, dass der Anteil langfristig orientierter Insider, die nicht handelsaktiv sind, gestiegen ist.

Da Daten aus anderen europäischen Staaten infolge abweichender wirtschaftlicher Rahmenbedingungen, steuerrechtlicher Regelungen und Offenlegungsvorschriften nicht zur Verfügung stehen, ist die Bildung einer geeigneten Kontrollgruppe zur verwendeten Stichprobe nicht möglich.

Der vorliegende Beitrag ist wie folgt aufgebaut: Kap. 2 gibt einen rechtlichen Überblick über die in Deutschland geltenden Regelungen zur Offenlegung von Insidergeschäften sowie über die wesentlichen Änderungen in der Besteuerung privater Aktienveräußerungen durch die Steuerreform 2009. Kap. 3 enthält einen Überblick über den bisherigen Forschungsstand zum Lock-in-Effekt und zum Einfluss von Steuern auf die Haltedauer bei privaten Veräußerungsgeschäften. In Kap. 4 werden

\footnotetext{
1 Für einen Literaturüberblick vgl. Kap. 3.
} 
die Insidermeldungen ausgewertet und Insidergeschäfte identifiziert und analysiert. Kap. 5 umfasst die empirische Auswertung der Haltedauern von Insidergeschäften. Der Beitrag schließt mit einer Zusammenfassung in Kap. 6.

\section{Rechtlicher Überblick}

\subsection{Gesetzliche Offenlegungspflichten in Zusammenhang mit Insidergeschäften am deutschen Kapitalmarkt}

Eine verbindliche Publizitätspflicht für Insidergeschäfte wurde in Deutschland erstmals im Rahmen des Vierten Finanzmarktförderungsgesetzes im Juli 2002 geschaffen. Im Oktober 2004 wurde eine Anpassung der ursprünglichen Regelung des $\S 15$ a Wertpapierhandelsgesetz (WpHG) durch das Anlegerschutzverbesserungsgesetz (AnSVG) notwendig, um der europäischen Marktmissbrauchsrichtlinie zu entsprechen. In diesem Zusammenhang wurde unter anderem der Kreis der Insider erweitert und das Insiderhandelsverbot auf alle Finanzinstrumente ausgedehnt. ${ }^{2}$

Von der Meldepflicht betroffen sind nach $\S 15 \mathrm{a}$ Abs. $1 \mathrm{WpHG}$ Mitglieder des Leitungs-, Verwaltungs- oder Aufsichtsorgans, persönlich haftende Gesellschafter und seit Oktober 2004 auch sonstige Führungspersonen (insbesondere Generalbevollmächtigte und Mitglieder eines erweiterten Vorstands), die regelmäßig Zugang zu Insiderinformationen und wesentlichen Einfluss auf strategische Entscheidungen haben. Im Unterschied zur alten Fassung von § 15a WpHG zählen Personen, die bei Tochter- oder Muttergesellschaften des ausgebenden Unternehmens beschäftigt sind, nun nicht mehr zum Kreis der Meldepflichtigen. ${ }^{3}$ Um eine Umgehung der Mitteilungspflicht zu erschweren, sind gemäß § 15a Abs. 3 WpHG auch sogenannte nahestehende Personen, die mit den oben genannten Organmitgliedern in enger Beziehung stehen, meldepflichtig. Von dieser Regelung werden Ehegatten, eingetragene Lebenspartner, unterhaltsberechtigte Kinder und andere Verwandte, die seit mindestens einem Jahr mit der Führungsperson im selben Haushalt leben, erfasst. ${ }^{4}$

Die Publizitätspflicht entsteht im Falle eines Handels mit Wertpapieren von so genannten auslösenden Emittenten nach $\S 15 a$ Abs. 1 Satz 3 und 4 WpHG. Dabei handelt es sich vor allem um Unternehmen, deren Aktien zum Handel an einer deutschen Börse zugelassen sind. Meldepflichtig sind alle Geschäfte eines auslösenden Emittenten mit Aktien oder anderen Finanzinstrumenten, die sich auf solche Aktien beziehen und somit auch der Erwerb bzw die Ausübung von Optionen. Ausgenommen sind Erbschaften und Schenkungen von Aktien oder von Finanzinstrumenten und der Erwerb sowie die Ausübung von Optionen, die als Vergütungsbestandteil gewährt wurden und der damit zusammenhängende Erwerb von Wertpapieren. ${ }^{5}$

\footnotetext{
2 Vgl. Osterloh (2007), S. $47 \mathrm{f}$.

3 Vgl. Osterloh (2007), S. 390.

4 Vgl. von Butlar (2003), S. 2133.

5 Vgl. Bundesanstalt für Finanzdienstleistungsaufsicht (2013). Im Zuge der Datenerhebung wurde jedoch festgestellt, dass derartige Geschäfte dennoch häufig gemeldet werden.
} 
Bis 2004 waren Transaktionen, die ein Gesamtvolumen von $25.000 €$ innerhalb von 30 Tagen nicht überschritten, von der Meldepflicht befreit. ${ }^{6}$ Mit der Anpassung durch das AnSVG wurde diese Grenze nach $\S 15$ a Abs. 1 letzter Satz WpHG auf ein Gesamtvolumen von $5000 €$ im Kalenderjahr verringert. Bei der Berechnung werden die Transaktionen der nahestehenden Personen dem jeweiligen Mitglied des Leitungs-, Verwaltungs- oder Aufsichtsorgans zugerechnet. Wird der Grenzbetrag überschritten, müssen alle getätigten Transaktionen nachträglich gemeldet werden. ${ }^{7}$

Das Insidergeschäft muss nach $\S 15 a$ Abs. 1 Satz $1 \mathrm{WpHG}$ innerhalb von fünf Werktagen bei der Bundesanstalt für Finanzdienstleistungsaufsicht (BaFin) und dem ausgebenden Unternehmen gemeldet werden. Dieses muss die Mitteilung unverzüglich veröffentlichen. Darunter wird regelmäßig der auf die Meldung folgende Arbeitstag verstanden. Im Regelfall muss eine Veröffentlichung auf der Internetseite des Emittenten für mindestens einen Monat erfolgen. ${ }^{8}$

Wird die Publizitätspflicht nicht, nicht richtig, nicht vollständig, nicht rechtzeitig oder nicht in der vorgeschriebenen Weise erfüllt, kann dieser Verstoß mit einer Geldbuße von bis zu $100.000 €$ geahndet werden. Für die Kontrolle und Verhängung der Sanktionen ist die BaFin zuständig. Sie kann dazu auch Auskunft und Unterlagen von Meldepflichtigen verlangen. ${ }^{9}$

\subsection{Gesetzliche Regelungen zur Besteuerung privater Veräußerungsgewinne in Deutschland}

Mit dem Unternehmenssteuerreformgesetz (UStRG) 2008 wurde nicht nur die deutsche Unternehmensbesteuerung reformiert, sondern es wurden auch weitreichende Änderungen in der Besteuerung von Kapitaleinkünften vorgenommen.

Gewinne aus der Veräußerung von Kapitalanlagen im Privatvermögen waren bis 2008 nur steuerpflichtig, wenn die Haltedauer innerhalb der einjährigen Spekulationsfrist nach $\S 23$ Abs. 1 Einkommensteuergesetz (EStG) lag. Einkünfte aus Spekulationsgeschäften zählten zu den sonstigen Einkünften nach § 22 EStG. Lag die Haltedauer außerhalb der Spekulationsfrist, so wurden Wertsteigerungen im Privatvermögen nur besteuert, wenn es sich um eine wesentliche Beteiligung handelte, der Verkäufer also innerhalb der letzten fünf Jahre zu mindestens $1 \%$ beteiligt war. Diese Gewinne wurden durch $\S 17$ EStG zu gewerblichen Einkünften umqualifiziert. Verluste aus privaten Veräußerungsgeschäften durften nach $\S 23$ Abs. 3 EStG nur mit Gewinnen aus privaten Veräußerungsgeschäften ausgeglichen werden. Ein Verlustvortrag oder Verlustrücktrag innerhalb der privaten Veräußerungsgeschäfte war möglich, eine Verrechnung mit anderen positiven Einkünften nicht. Zum 31.12.2008 vorhandene Verlustvorträge aus privaten Veräußerungsgeschäften konnten gemäß $\S 23$ Abs. 3 EStG mit späteren Veräußerungsgewinnen, die der Abgeltungssteuer unterlagen, verrechnet werden. ${ }^{10}$

\footnotetext{
6 Vgl. Weiler und Tollkühn (2002), S. 1923.

7 Vgl. Bundesanstalt für Finanzdienstleistungsaufsicht (2013).

8 Vgl. Pluskat (2005), S. 1110.

9 Vgl. Weiler und Tollkühn (2002), S. 1925.

10 Diese Möglichkeit bestand bis zum 31.07.2014.
} 
Seit der Einführung der Abgeltungssteuer ab 01.01.2009 zählen Wertsteigerungen, die durch die Veräußerung von Kapitalanlagen im Privatvermögen realisiert werden, zu den Einkünften aus Kapitalvermögen nach $§ 20$ Abs. 2 EStG. Die einjährige Spekulationsfrist entfällt damit. Die Einkünfte aus Kapitalvermögen unterliegen einer einheitlichen Abgeltungssteuer nach $\S 32 \mathrm{~d}$ EStG in der Höhe von $25 \%$ (26,38\% inkl. Solidaritätszuschlag), die in der Regel durch Einbehalt der Kapitalertragsteuer erhoben wird. Die Einkommensteuer auf die Einkünfte aus Kapitalvermögen ist damit abgegolten und die betroffenen Erträge werden nicht mehr progressionserhöhend berücksichtigt.

Da die Einkünfte aus Kapitalvermögen einem eigenen Steuersatz unterliegen, ist ein Verlustausgleich mit den anderen Einkunftsarten gemäß $§ 20$ Abs. 6 EStG nicht möglich. Zudem dürfen Verluste aus Aktienverkäufen nach § 20 Abs. 1 EStG nur mit Gewinnen aus Aktienverkäufen verrechnet werden. Gemäß $§ 20$ Abs. 6 EStG besteht jedoch die Möglichkeit, Verluste aus der Veräußerung von Aktien mit positiven Einkünften aus der Veräußerung von Aktien in Folgejahren zu verrechnen (,einkunftsquellenspezifischer Verlustvortrag“). Ein Verlustrücktrag ist jedoch nicht mehr möglich.

Sämtliche Neuregelungen durch das UStRG 2008 gelten ab dem Veranlagungszeitraum 2009. Für Wertpapiere, die vor dem 01.01.2009 angeschafft wurden, gibt es jedoch einen Bestandsschutz nach $§ 52 \mathrm{a}$ Abs. 10 EStG, sodass bei ihrer Veräußerung noch die bis 2008 geltende Rechtslage zur Anwendung kommt.

\section{Bisherige Untersuchungsergebnisse zum Lock-in-Effekt und zum Einfluss von Steuern auf die Haltedauer von Wertpapieren}

Bereits seit den 1960er-Jahren wird in der Literatur der sogenannte Lock-in-Effekt der Besteuerung privater Veräußerungsgewinne diskutiert. ${ }^{11}$ Dieser besagt, dass die Realisation von Veräußerungsgewinnen verschoben wird, um so zugleich die Besteuerung aufzuschieben. Besonders ausgeprägt ist dieser Lock-in-Effekt, wenn die Besteuerung von Veräußerungsgewinnen nicht einheitlich erfolgt, sondern besondere Regeln einen begünstigen Steuersatz zB für langfristige Veräußerungsgewinne vorsehen oder die Besteuerung $\mathrm{ab}$ einer bestimmten Mindesthaltedauer gänzlich entfällt. ${ }^{12}$

Die Frage, ob eine Veräußerungsgewinnbesteuerung einen Einfluss auf die Haltedauer von privaten Anlegern hat, wurde in der Literatur bisher kaum empirisch untersucht. ${ }^{13}$ Dies ist darauf zurückzuführen, dass Primärdaten zu Haltedauern kaum zugänglich sind, da (aggregierte) Daten der Steuerstatistik bestenfalls Auskunft über die Höhe der deklarierten Veräußerungsgewinne und -verluste geben. Die Realisation

\footnotetext{
11 Vgl. Holt und Shelton (1961) und Sprinkel und West (1962).

12 Für Studien, die den Lock-in-Effekt am US-amerikanischen Kapitalmarkt untersuchen, siehe Lang und Shackelford (2000), Ayers et al. (2008) sowie Dai et al. (2008). Den Zusammenhang von erwarteter Haltedauer und Kursgewinnbesteuerung untersuchen Liang et al. (2002).

13 Ein realoptionsbasiertes Modell zum Einfluss der Kursgewinnbesteuerung auf den optimalen Investitions- und Desinvestitionszeitpunkt entwickeln Niemann und Sureth (2013).
} 
von steuerfreien Veräußerungsgewinnen scheint jedoch in Daten der Steuerstatistik nicht auf.

Cook und O'Hare (1992) entwickeln ein Modell des Einflusses der Kursgewinnbesteuerung auf die Haltedauern von Wertpapieren durch Investoren auf Basis der Optimal Stopping Theory und testen dieses anhand von US-amerikanischen Daten der Jahre 1985-1987. Sie weisen darauf hin, dass bereits geringfügige Änderungen der durchschnittlichen Haltedauer wesentliche Auswirkungen auf das aggregierte Veräußerungsverhalten und damit auf das Steueraufkommen aufweisen.

Die einzige Studie für den US-amerikanischen Markt, die investorspezifische Daten zum Veräußerungszeitpunkt verwendet, stammt von Landsman und Shackelford (1995). Im Zuge der fremdfinanzierten Übernahme des Unternehmens RJR Nabisco wurden den Autoren die kompletten Informationen hinsichtlich des Verkaufszeitpunktes der Altaktionäre zur Verfügung gestellt. Somit können die Autoren analysieren, wann die bisherigen Aktionäre ihre Anteile zum Verkauf anboten und welche steuerlichen Konsequenzen aus ihrem Verhalten resultierten. Zudem können sie für jeden Aktionär die Höhe des realisierten Veräußerungsgewinnes sowie die Haltedauer berechnen und diese in Bezug zum Aktienkurs des Unternehmens setzen. Die Autoren zeigen einen starken Lock-in-Effekt für steuerpflichtige Privataktionäre, der sich in einer signifikant negativen Relation zwischen den aggregierten steuerpflichtigen Veräußerungsgewinnen und dem Aktienkurs des Verkaufstages manifestiert. ${ }^{14}$ Die Verallgemeinerbarkeit der Ergebnisse der Studie ist angesichts der Verwendung von Daten nur eines Unternehmens in der speziellen Situation eines Leveraged BuyOuts fraglich; zudem liegt der Untersuchungszeitraum bereits weit in der Vergangenheit und es fanden im Untersuchungszeitraum keine Änderungen in der Besteuerung von privaten Veräußerungsgewinnen statt, die Rückschlusse über eine Lockerung bzw Verschärfung des Lock-in-Effekts zulassen würden. Wenngleich der Verkaufszeitpunkt für jeden einzelnen Investor beobachtet werden kann, werden zudem die Haltedauern von den Autoren nicht statistisch ausgewertet.

Daneben existieren weitere Studien für den US-amerikanischen, australischen und deutschen Kapitalmarkt, die aufgrund der Wahl der Stichprobe ebenfalls in der Lage sind, Haltedauern der Aktionäre zu approximieren. Alle Studien verwenden für die Generierung der Stichprobe nur Unternehmen, deren Gang an die Börse (IPO) im Untersuchungszeitraum stattgefunden hat. Da das Datum des Börsenganges bekannt ist, kann daraus die Haltedauer der Erstaktionäre zu jedem Zeitpunkt berechnet werden.

Die Studie von Reese (1998) verwendet Daten von US-Unternehmen, die im Beobachtungszeitraum 1976-1995 erstmals an der Börse notierten. In den Beobachtungszeitraum fällt auch die Steuerreform 1986, durch die der Steuersatz auf langfristige Veräußerungsgewinne (Haltedauer über einem Jahr) angehoben wurde. Die Analyse von Transaktionsvolumina und Aktienkursen rund um die steuerlich relevante Haltedauer von einem Jahr zeigt, dass im Fall einer positiven Aktienkursentwicklung die Veräußerung unmittelbar nach Erreichen der Grenze für langfristige Veräußerungsgewinne stattfindet, während im Falle einer negativen Aktienkursent-

14 Vgl. Landsman und Shackelford (1995), S. 245 ff. 
wicklung die Veräußerung unmittelbar davor stattfindet. ${ }^{15}$ Das Untersuchungsdesign von Reese (1998) replizieren Watrin und Benhof (2009) für 43 IPOs am deutschen Kapitalmarkt im Beobachtungszeitraum 2004 bis 2007. Auch ihre Ergebnisse zeigen, dass nach Ablauf der einjährigen Spekulationsfrist abnormale Handelsvolumina beobachtet werden können, die die Autoren auf den steuerlich motivierten Aufschub der Veräußerung von Aktien mit hohen Kursgewinnen zurückführen. ${ }^{16}$ Die Studie von Watrin und Benhof (2009) unterscheidet sich von der in diesem Beitrag durchgeführten Analyse durch zwei Faktoren: Einerseits werden in der Studie nur Veräußerungsgewinne betrachtet, während Veräußerungen, die zu einem Verlust führten, unberücksichtigt bleiben. Andererseits fällt der Beobachtungszeitraum ausschließlich in die Zeit des Halbeinkünfteverfahrens; ein Vergleich mit der derzeit gültigen Rechtslage, die keine steuerliche Differenzierung nach Haltedauern vorsieht, ist demnach nicht möglich.

Die Frage, ob Anleger ihr Veräußerungsverhalten durch die Steuerreform 2009 verändert haben, kann mit Daten der amtlichen Steuerstatistiken nicht beantwortet werden. Während unter dem Halbeinkünfteverfahren Veräußerungsgewinne außerhalb der Spekulationsfrist steuerfrei waren und somit in der Steuerstatistik nicht erfasst sind, erfolgt unter der Abgeltungssteuer aufgrund des Abgeltungscharakters des besonderen Steuersatzes von $25 \%$ generell keine Meldung von Veräußerungsgewinnen im Rahmen der Veranlagung. Für beide Beobachtungszeiträume stehen somit keine geeigneten Daten aus der Einkommensteuerstatistik zur Verfügung.

Der vorliegende Beitrag verwendet erstmals Daten aus Insidergeschäften zur Bearbeitung einer steuerlichen Fragestellung, indem die an die BaFin übermittelten und öffentlich verfügbaren Meldungen verwendet werden, um Insidergeschäfte zu identifizieren und daraus Haltedauern und die Höhe des realisierten Veräußerungsgewinnes bzw -verlustes zu berechnen. Damit kann für den deutschen Markt erstmals eine steuerlich motivierte Analyse von Haltedauern in Kombination mit der Höhe des realisierten Veräußerungsgewinnes oder -verlustes auf Anlegerebene durchgeführt werden, bei der nicht die aggregierten Veräußerungsgewinne bzw -verluste eines Steuerpflichtigen, sondern jeder einzelne realisierte Veräußerungsvorgang die Datenbasis bildet. ${ }^{17}$

\section{Stichprobenauswahl}

\subsection{Erhebung der Insidertransaktionen}

Da die Datenbank der BaFin das gesetzliche Veröffentlichungsmedium für Insidertransaktionen ist, wird diese als Primärquelle verwendet. Aus dieser Datenbank können folgende Daten für Insidertransaktionen entnommen werden:

\footnotetext{
15 Vgl. Reese (1998), S. 1799 ff. Weitere Untersuchungen, die auf IPOs zurückgreifen, aber keine Analyse der Haltedauern durchführen, stammen von Blouin et al. (2002) für den US-Markt sowie Hanlon und Pinder (2007) für den australischen Markt.

16 Vgl. Watrin und Benhof (2009), S. $300 \mathrm{f}$.

17 Für eine Analyse mittels aggregierter Daten der deutschen Steuerstatistik siehe Jacob (2013).
} 
- Name, Bezeichnung des Wertpapiers und Wertpapierkennnummer des ausgebenden Unternehmens,

- Berufliche Rolle der meldepflichtigen Person (Aufsichtsorgan, geschäftsführendes Organ, sonstige Führungsperson, Person in enger Beziehung),

- Art der Transaktion (Kauf oder Verkauf),

- Stückzahl, Währung, Kurs,

- Handelsplatz,

- Handels-, Veröffentlichungs- und Meldedatum.

Der Name der meldepflichtigen Person ist aus datenschutzrechtlichen Gründen nur für Transaktionen der letzten zwölf Monate ersichtlich. Da jedoch der Name der meldepflichtigen Person für verschiedene Analysen erforderlich ist, wird die private Homepage „Infopool für meldepflichtige Wertpapiergeschäfte“, aufrufbar unter www.insiderdaten.de, als zusätzliche Quelle verwendet, da diese auch die Namen der Insider veröffentlicht. Zusätzlich werden auch die Homepages und Jahresabschlüsse der Emittenten verwendet, um fehlende Daten, wie zum Beispiel die genaue Position des Unternehmensinsiders, zu ergänzen und nicht plausible Transaktionen zu überprüfen bzw zu berichtigen. Abgesehen vom Namen des Insiders ist dessen berufliche Rolle im Unternehmen der einzige personenspezifische Inhalt, der über die Datenbank abgerufen werden kann. Weitere personenspezifische Merkmale, wie zB Alter, Dauer der Unternehmenszugehörigkeit, Bruttolohn oder Einkommen, können daher nicht in die Analyse einbezogen werden.

Untersucht werden alle gemeldeten Aktientransaktionen im Zeitraum von 01.07.2002 bis 30.06.201418, die gelistete DAX30-, MDAX- oder TecDAX-Unternehmen (zum Stichtag 30.06.2014) betreffen. Die Gesamtstichprobe umfasst damit 110 ausgebende Unternehmen.

Die Datenbank der BaFin enthält für den Zeitraum 01.07.2002-30.06.2014 7994 gemeldete Transaktionen, die Unternehmen der Stichprobe betreffen. Von diesen verfügbaren Meldungen wurden folgende Bereinigungen durchgeführt:

Transaktionen von juristischen Personen werden nicht beachtet, da deren Veräußerungsgewinne nach $\S 8 \mathrm{~b}$ Abs. 1 Körperschaftsteuergesetz (KStG) bereits vor 2009 unabhängig von der Haltedauer steuerfrei waren. Wenngleich diese Transaktionen idealerweise zur Generierung einer Kontrollgruppe verwendet werden könnten, musste dieser Ansatz aufgrund der zu geringen Anzahl daraus identifizierbarer Geschäfte (20 einander zuordenbare Käufe und Verkäufe) verworfen werden. Da mit deutschen Daten die Bildung einer Kontrollgruppe nicht möglich ist, verbleibt als einziger alternativer Ansatz zur Generierung einer Kontrollgruppe die Verwendung eines ausländischen Datensatzes. In Österreich existieren seit 01.01.2005 ebenfalls Regelungen zur Meldepflicht von Insidergeschäften, und Geschäfte von Insidern werden über die Homepage der österreichischen Finanzmarktaufsicht (FMA) öffentlich gemacht. Die geringe Anzahl von Meldungen im Untersuchungszeitraum war jedoch nicht ausreichend für die Bildung einer Kontrollgruppe. Da die Rechtslage und -entwicklung sowie die wirtschaftlichen Rahmenbedingungen von anderen aus-

$\overline{18}$ Der Beginn der Erhebung ist definiert durch die erstmalige Verpflichtung zur Veröffentlichung von Insidergeschäften durch das Vierte Finanzmarktförderungsgesetz ab 01.07.2002, siehe Abschn. 2.1. 
ländischen Staaten sich im Untersuchungszeitraum grundlegend von der deutschen Situation unterscheiden, erscheint die Bildung einer alternativen ausländischen Kontrollgruppe im vorliegenden Fall nicht zweckmäßig.

Während Optionsausübungen und die Ausübung von Bezugsrechten generell in die Untersuchung einfließen, da sie Aktienerwerbe darstellen, werden Transaktionen mit virtuellen Optionen (Stock Appreciation Rights) und Erwerbs- und Veräußerungsvorgänge von Optionen sowie der Kauf und Verkauf von Bezugsrechten nicht berücksichtigt, um auf die Effekte des Steuersystemwechsels auf die Haltedauer von Aktien zu fokussieren. Andere Finanzinstrumente werden bewusst ausgeblendet, da für deren Haltedauern andere steuerliche und nichtsteuerliche Überlegungen ausschlaggebend sein können. Tauschvorgänge, Käufe und Verkäufe von sonstigen Wertpapieren, wie zB Anleihen und Zertifikaten und sonstige Transaktionen, wie außerbörsliche Käufe, unentgeltliche Einbringungen und Umwandlungsvorgänge werden nicht in die Stichprobe einbezogen. Zusätzlich wird die Datenmenge noch um Doppelmeldungen bzw fehlerhafte Transaktionen bereinigt. Nach Durchführung der Bereinigungsschritte verbleiben 5650 Insidermeldungen von 1048 Insidern als endgültige Stichprobe.

Die in der Datenbank der BaFin enthaltenen Angaben zur Position des Insiders werden zur weiteren Analyse in vier Gruppen zusammengefasst: Mitglieder der Vorstands, des Aufsichtsrates, sonstige Führungspersonen sowie nahestehende Personen. Von den 1048 Insidern waren 961 selbst im Unternehmen tätig, während $87(8,30 \%)$ nahestehende Personen sind. Unter den im Unternehmen tätigen

Tab. 1 Stichprobengenerierung

\begin{tabular}{ll}
\hline & Anzahl \\
\hline Gemeldete Transaktionen von 01.07.2002 bis & 7994 \\
30.06.2014 & \\
Transaktionen von juristischen Personen & -854 \\
Stock Appreciation Rights & -515 \\
Käufe/Verkäufe von Bezugsrechten, Optionen oder & $-669^{19}$ \\
sonstigen Wertpapieren; sonstige Transaktionen & \\
Tauschvorgänge & -65 \\
Doppelte Meldungen & -26 \\
Fehlerhafte Meldungen & -215 \\
Verbleibende Meldungen & 5650 \\
\hline
\end{tabular}

Diese Tabelle gibt einen Überblick über die Auswahl der für die Stichprobe verwendeten Meldungen der Insider. Nach Bereinigungen wurden 5650 Insidermeldungen in die Stichprobe aufgenommen, aus denen in weiterer Folge Insidergeschäfte gebildet wurden

\footnotetext{
19 Optionen können als Substitute für Aktien angesehen werden, weshalb Meldungen über den Kauf und Verkauf von Optionen grundsätzlich zur Identifikation von Optionsgeschäften herangezogen werden könnten. Aus den 669 entfernten Meldungen können jedoch nur zwölf Optionsgeschäfte identifiziert werden, von denen vier auf den Zeitraum des Halbeinkünfteverfahrens und acht auf den Zeitraum der Abgeltungssteuer entfallen. Für eine umfassende empirische Auswertung ist diese Anzahl nicht ausreichend. Ein Vergleich der beiden Mittelwerte zeigt jedoch auch hier eine Reduktion der durchschnittlichen Haltedauer von 323,25 Tagen unter dem Halbeinkünfteverfahren auf 185,13 unter der Abgeltungssteuer.
} 
Insidern überwiegen Vorstände (598 Personen, 57,06\%), gefolgt von Aufsichtsratsmitgliedern (306 Personen, 29,19\%) und sonstigen Führungspersonen (57 Personen, $5,43 \%)$.

\subsection{Identifikation von Insidergeschäften}

Im nächsten Schritt werden die 5650 Meldungen der Insider (siehe Tab. 1 in Abschn. 4.1) herangezogen, um Insidergeschäfte zu identifizieren. Es wird, sofern möglich, jedem Verkauf eines Insiders ein früherer Kauf derselben Person zugeordnet. Dabei wird dem FIFO-Prinzip (First in - First out) gefolgt, da dieses auch bei der gesetzlichen Berechnung der Abgeltungssteuer Anwendung findet ( $\$ 20$ Abs. 4 Z 7 EStG) ${ }^{20}$ Da der Anfangsbestand von Wertpapieren, die von den Insidern gehalten werden, nicht beobachtet werden kann, wird angenommen, dass die Insider zu Beginn des Untersuchungszeitraumes keine Aktien besaßen. ${ }^{21}$

Tab. 11 im Anhang zeigt anhand eines konkreten Beispiels, wie die Identifikation von Insidergeschäften, basierend auf den verfügbaren Meldungen, vorgenommen wurde.

Die identifizierten Insidergeschäfte werden je nach Datum des Kaufs einer der beiden Steuerperioden zugerechnet. Der erste Zeitraum (Halbeinkünfteverfahren) wird allen Käufen zwischen 01.07.2002 und 31.12.2008 zugewiesen, der zweite Zeitraum (Abgeltungssteuer) allen Käufen beginnend mit 01.01.2009.

\subsection{Anzahl an identifizierten Geschäften, Transaktionsvolumina und Überblick über die Insider}

Die 5650 Meldungen, die der BaFin-Datenbank entnommen werden konnten, teilen sich in 3400 gemeldete Käufe und 2250 gemeldete Verkäufe von Insidern.

2460 der 3400 Käufe (72,35\%) konnte kein Verkauf zugeordnet werden, 940 Käufen $(27,65 \%)$ konnten ein Verkauf bzw mehrere Verkäufe zugeordnet werden. 1412 der 2250 Verkäufe $(62,75 \%)$ konnte kein Kauf zugeordnet werden, 555 Verkäufen $(24,67 \%)$ konnte ein Kauf zugeordnet werden und 283 Verkäufe $(12,58 \%)$ mussten in 795 Teilverkäufe aufgeteilt werden. 656 der 795 Teilverkäufe $(82,51 \%)$ konnte ein Kauf zugeordnet werden und in 139 Fällen $(17,49 \%)$ war keine Zuordnung möglich.

Insgesamt konnten aus der Stichprobe somit $555+656=1211$ Insidergeschäfte identifiziert werden, die von 383 Insidern durchgeführt wurden. Davon werden 922 Geschäfte $(76,14 \%)$ dem Zeitraum des Halbeinkünfteverfahrens und 289 Geschäfte $(23,86 \%)$ dem Zeitraum der Abgeltungssteuer zugeordnet.

\footnotetext{
20 Bei der Berechnung der Abgeltungssteuer ist zu berücksichtigen, dass das FIFO-Prinzip jeweils nur auf Ebene des einzelnen Depots angewandt wird und somit die Zuordnung bei Insidern mit mehreren Depots anders ausfallen kann, als bei Insidern, die ihre Aktien in einem Depot halten. Aus der Datenbasis geht nicht hervor, ob der Aktienbesitz der Insider auf mehrere Depots verteilt ist, weshalb zunächst von nur einem Depot pro Insider ausgegangen wird. Diese Annahme wird in der Sensitivitätsanalyse Abschn. 5.5. durch Verwendung der Unterstichprobe F aufgehoben.

21 Diese restriktive Annahme wird in der Sensitivitätsanalyse in Abschn. 5.5. durch Verwendung der Unterstichproben $\mathrm{C}$ und $\mathrm{D}$ aufgehoben.
} 


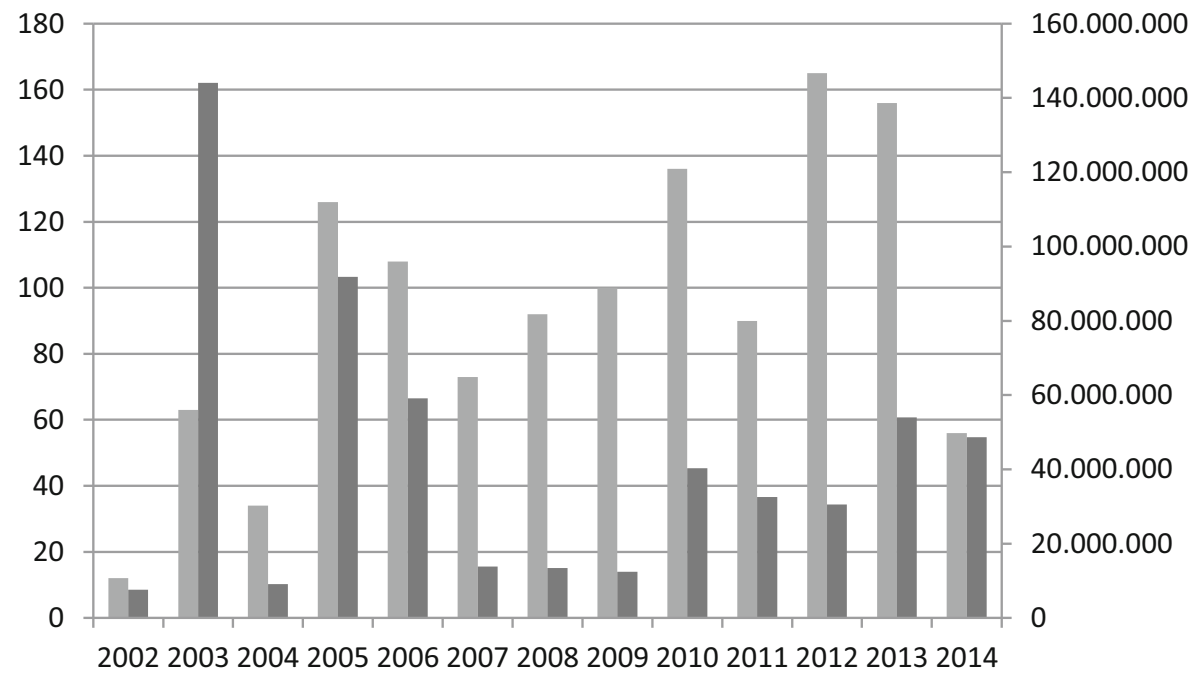

Anzahl Volumen

Abb. 1 Anzahl und kumuliertes Transaktionsvolumen der identifizierten Insidergeschäfte, 2002-2014. (Die linke Skala dieser Abbildung zeigt die Anzahl an identifizierten Insidergeschäften, die rechte Skala das kumulierte Transaktionsvolumen (in EUR, bewertet zu Verkaufspreisen) der identifizierten Insidergeschäfte für die Jahre 2002-2014. Der Auswertung liegen 1211 identifizierte Insidergeschäfte von 383 Insidern zu Grunde.)

Abb. 1 gibt einen Überblick über die zeitliche Verteilung der Anzahl der identifizierten Insidergeschäfte sowie die damit in Zusammenhang stehenden kumulierten Transaktionsvolumina, bewertetet zu Verkaufspreisen..$^{22}$

Wie aus Abb. 1 ersichtlich ist, wurde in den Jahren 2012 und 2013 die höchste Anzahl an Insidergeschäften (mehr als ein Viertel aller identifizierten Geschäfte) realisiert. 2009, das Jahr des Inkrafttretens der Steuerreform, ist gemessen an der Anzahl der Insidergeschäfte nur das sechstwichtigste. 2003 und 2005 sind die Jahre mit dem höchsten wertmäßigen Transaktionsvolumen. Der hohe Wert für 2005 kann unter Umständen durch die Senkung des meldepflichtigen Volumens auf $5000 €$ im Kalenderjahr (siehe Abschn. 2.1.) zurückgeführt werden. Relativiert man das jährliche Transaktionsvolumen über die Anzahl der Geschäfte pro Jahr, so zeigt sich, dass 2003 und 2014 die Jahre mit den höchsten relativen Transaktionsvolumina waren. Insgesamt kann also nach einem anfänglichen Boom ein Rückgang der relativen Transaktionsvolumina aus Insidergeschäften beobachtet werden, der erst in den letzten Jahren wieder umgekehrt wurde.

\footnotetext{
${ }^{22}$ Drei Insidergeschäfte der Jahre 2003 und 2006 weisen außergewöhnlich hohe Transaktionsvolumina auf. Diese umfassen mehr als die Hälfte des gesamten Transaktionsvolumens im jeweiligen Jahr und sind zugleich um mehr als das Vierfache höher als das nächstgrößte beobachtete Transaktionsvolumen in der Gesamtstichprobe. Um Verzerrungen durch diese Geschäfte zu vermeiden, wurden sie in dieser Abbildung nicht berücksichtigt.
} 
Der Zeitpunkt der Einführung der Abgeltungssteuer fällt eng mit dem Ausbruch der globalen Finanz- und Wirtschaftskrise zusammen. Diese könnte Insider vor allem im Zeitraum 2008-2010 veranlasst haben, vermehrt Portfolioumschichtungen vorzunehmen, die einerseits nicht steuerlich motiviert waren und die andererseits zu einer Verkürzung der Haltedauer geführt haben. Betrachtet man die Transaktionsvolumina sowie die Anzahl der identifizierten Geschäfte im Zeitraum 2008-2010, so zeigt sich jedoch, dass diese Jahre in Bezug auf den gesamten Untersuchungszeitraum hinsichtlich des Transaktionsvolumens im hinteren Drittel und hinsichtlich der Anzahl der Geschäfte lediglich im Mittelfeld liegen. Eine krisenbedingte Zunahme an Portfolioumschichtungen erscheint daher wenig plausibel.

Die 1211 identifizierten Insidergeschäfte wurden von insgesamt 383 Insidern abgewickelt. ${ }^{23}$ Für 123 Insider konnte genau ein Geschäft identifiziert werden, während der Mittelwert (Median) an identifizierten Geschäften pro Insider bei 7,37 (6) liegt. Der höchste beobachtete Wert liegt bei 27 identifizierten Geschäften pro Insider.

Die in der Datenbank der BaFin enthaltenen Angaben zur Position des Insiders, wie in Abschn. 4.1. bereits erwähnt, in vier Gruppen zusammengefasst: Mitglieder der Vorstands, des Aufsichtsrates, sonstige Führungspersonen sowie nahestehende Personen. Von den 383 Personen waren 353 selbst in ihrem Unternehmen tätig und 30 Personen $(7,83 \%)$ wurden als nahestehende Personen gemeldet. Unter den im Unternehmen tätigen Insidern überwiegen Vorstände (179 Personen, 46,74\%), gefolgt von Aufsichtsratsmitgliedern (135 Personen, 35,25\%) und sonstigen Führungspersonen (39 Personen, 10,18\%). Personen aus dem Vorstand stellen nicht nur die größte Gruppe an Insidern, sondern sind auch für die überwiegende Mehrheit an identifizierten Insidergeschäften verantwortlich. Von den 1211 identifizierten Insidergeschäften entfallen 742 Geschäfte $(61,27 \%)$ auf Mitglieder des Vorstands und 318 Geschäfte $(26,26 \%)$ auf Mitglieder des Aufsichtsrates. Im Gegensatz dazu spielen sonstige Führungspersonen (58 Geschäfte, 4,79\%) sowie nahestehende Personen (93 Geschäfte, 7,68\%) nur eine untergeordnete Rolle.

Die 1211 identifizieren Insidergeschäfte der 383 Insider verteilen sich auf 84 Unternehmen. Für elf der 84 Unternehmen konnte genau ein Geschäft identifiziert werden, der Mittelwert (Median) der identifizierten Geschäfte pro Unternehmen beträgt 31,63 (23). Für das Unternehmen mit der größten Anzahl an Geschäften konnten 98 Geschäfte identifiziert werden.

Da für jede gemeldete Insidertransaktion Daten zum Aktienkurs sowie zur gehandelten Stückzahl übermittelt werden, kann für jedes identifizierte Geschäft auch der zugehörige Veräußerungsgewinn bzw -verlust berechnet werden. Tab. 2 gibt einen Überblick über die Mittelwerte der Transaktionsvolumina (bewertet zu Verkaufspreisen), der Veräußerungsgewinne und -verluste sowie über den Anteil an Verlustgeschäften für die Gesamtstichprobe sowie nach Insidergruppen getrennt.

\footnotetext{
23 Da es sich bei den betrachteten Insidern überwiegend um Mitglieder des Vorstandes oder Aufsichtsrats deutscher Kapitalgesellschaften handelt, treffen wir die Annahme, dass alle untersuchten Personen in Deutschland unbeschränkt steuerpflichtig bzw im Fall von mehrfachen unbeschränkten Steuerpflichten in Deutschland DBA-rechtlich ansässig sind. Für nicht in Deutschland ansässige natürliche Personen dürfte die Änderung der Veräußerungsgewinnbesteuerung idR irrelevant gewesen sein. Wir gehen davon aus, dass die Anzahl der nicht in Deutschland ansässigen Personen in der Stichprobe vernachlässigbar ist.
} 
Tab. 2 Mittelwerte der Transaktionsvolumina, der Veräußerungsgewinne und -verluste sowie Anteil an Verlustgeschäften

\begin{tabular}{llllll}
\hline & $\begin{array}{l}\text { Gesamtstich- } \\
\text { probe }\end{array}$ & Vorstand & Aufsichtsrat & $\begin{array}{l}\text { Sonstige } \\
\text { Führungs- } \\
\text { person }\end{array}$ & $\begin{array}{l}\text { Nahestehende } \\
\text { Person }\end{array}$ \\
\hline $\begin{array}{l}\text { Transaktionsvolumen } \\
\text { (EUR) }\end{array}$ & 745.019 & 393.672 & 1.323 .123 & 858.714 & 1.497 .901 \\
$\begin{array}{l}\text { Veräußerungsgewinn } \\
\text { (EUR) }\end{array}$ & 382.801 & 151.895 & 897.783 & 169.166 & 597.408 \\
$\begin{array}{l}\text { Veräußerungsverlust } \\
\text { (EUR) }\end{array}$ & -28.441 & -25.415 & -42.601 & -103 & -21.834 \\
$\begin{array}{l}\text { Anteil an Verlust- } \\
\text { geschäften }(\%)\end{array}$ & 18,91 & 21,70 & 16,67 & 6,90 & 11,83 \\
\hline
\end{tabular}

Diese Tabelle bezieht sich auf die 1211 identifizierten Insidergeschäfte. Sie gibt einen Überblick über die Mittelwerte der Transaktionsvolumina (in EUR und bewertet zu Verkaufspreisen), der Veräußerungsgewinne und -verluste (jeweils in EUR) sowie über den Anteil an Verlustgeschäften (in \%) in der Gesamtstichprobe und nach Insidergruppen getrennt. Dabei wird, je nach Position des Insiders im Unternehmen, nach Mitgliedern des Vorstands, des Aufsichtsrates, sonstigen Führungspersonen und nahestehenden Personen unterschieden

Die Analyse der Transaktionsvolumina nach Position des Insiders zeigt, dass der Mittelwert des Handelsvolumens über alle Insidergeschäfte bei rund $745.000 €$ liegt, wobei dieser Wert vor allem von den hohen Transaktionsvolumina von Aufsichtsratsmitgliedern, sonstigen Führungspersonen und nahestehenden Personen getrieben wird und die durchschnittlichen Transaktionsvolumina von Mitgliedern des Vorstands deutlich unter dem Mittelwert der Gesamtstichprobe liegen. Ein ähnliches Bild zeigt die Verteilung der Höhe der Veräußerungsgewinne bzw -verluste auf die einzelnen Gruppen an Insidern: Erneut liegen die Werte für Aufsichtsratsmitglieder über den Mittelwerten der Gesamtstichprobe. Auffallend ist zudem, dass sonstige Führungspersonen und nahestehende Personen nicht nur deutlich geringere VeräuBerungsverluste realisieren als der Mittelwert der Gesamtstichprobe, sondern auch der Anteil an Verlustgeschäften in diesen beiden Gruppen sehr gering ist.

Wie aus Tab. 2 ersichtlich ist, resultiert der Großteil der identifizierten Insidergeschäfte (982 Geschäfte, 81,09\%) in einem Veräußerungsgewinn, während bei 229 Geschäften $(18,91 \%)$ ein Veräußerungsverlust erzielt wurde. Der Anteil der Verlustgeschäfte an der gesamten Anzahl an Geschäften ist in beiden Steuersystemen annähernd gleich hoch und beträgt rund $20 \%$. Hinsichtlich der Höhe der realisierten Veräußerungsgewinne bzw -verluste zeigen sich jedoch deutliche Unterschiede zwischen den beiden Steuersystemen: Während der durchschnittliche Veräußerungsgewinn unter dem Halbeinkünfteverfahren rund $252.000 €$ beträgt, liegt jener unter der Abgeltungssteuer bei rund 797.000 $€$ und ist somit mehr als drei Mal so hoch. Auch die Höhe des durchschnittlichen Veräußerungsverlustes steigt unter der Abgeltungssteuer und liegt bei rund $59.000 €$, während dieser Wert unter dem Halbeinkünfteverfahren nur bei rund $18.000 €$ liegt. 
Tab. 3 Portfoliostände und Portfoliowert der untersuchten Insider, 2002-2014

\begin{tabular}{|c|c|c|c|c|c|c|}
\hline Jahr & $\begin{array}{l}\text { Portfoliostand } \\
1.1 . \\
\text { (Stück) }\end{array}$ & $\begin{array}{l}\text { Käufe } \\
\text { (Stück) }\end{array}$ & $\begin{array}{l}\text { Verkäufe } \\
\text { (Stück) }\end{array}$ & $\begin{array}{l}\text { Portfolio- } \\
\text { Stand } \\
31.12 \text {. } \\
\text { (Stück) }\end{array}$ & $\begin{array}{l}\text { Portfoliowert } \\
(€ \text { zu AK) } \\
31.12\end{array}$ & $\begin{array}{l}\text { Verkäufe ( } € \text { zu } \\
\text { AK) } \\
\text { kumuliert }\end{array}$ \\
\hline 2002 & 0 & 6.178 .984 & 102. & 6.076 .187 & $276.030 .331,67$ & $9.606 .561,60$ \\
\hline 2003 & 6.076 .187 & 1.448 .972 & 228.185 & 7.296 .974 & $306.269 .897,88$ & $20.582 .443,59$ \\
\hline 2004 & 7.296 .974 & 513.594 & 219.753 & 7.590 .815 & $314.268 .480,11$ & $26.300 .404,21$ \\
\hline 2005 & 7.590 .815 & 2.686 .015 & 1.193 .248 & 9.083 .582 & $353.575 .307,89$ & $81.335 .328,12$ \\
\hline 2006 & 9.083 .582 & 2.674 .280 & 2.295 .343 & 9.462 .519 & $342.366 .188,26$ & $.572,44$ \\
\hline 2007 & 9.462 .519 & 3.340 .419 & 106.519 & 12.696 .419 & $434.090 .212,07$ & $186.287 .155,17$ \\
\hline 2008 & 12.696 .419 & 6.528 .368 & 1.707 .469 & 17.517.318 & $512.510 .496,06$ & 231.887.311,71 \\
\hline 2009 & 17.517 .318 & 3.113 .515 & 718.973 & 19.911 .860 & $526.449 .395,86$ & $241.027 .040,07$ \\
\hline 2010 & 19.911 .860 & 2.316 .140 & 2.154 .227 & 20.073 .773 & $574.276 .689,37$ & $266.660 .335,33$ \\
\hline 2011 & 20.073 .773 & 1.294 .491 & 1.305 .403 & 20.062 .861 & $574.151 .203,43$ & $292.267 .082,39$ \\
\hline 2012 & 20.062 .861 & 5.836 .254 & 5.943 .427 & 19.955 .688 & $532.940 .902,94$ & $588.687 .239,38$ \\
\hline 2013 & 19.955 .688 & 7.753 .803 & 1.625 .726 & 26.083 .765 & $595.064 .146,94$ & $639.192 .644,77$ \\
\hline 2014 & 26.083 .765 & 1.790 .712 & 3.076 .928 & 24.797 .549 & $589.356 .636,01$ & $697.612 .838,63$ \\
\hline
\end{tabular}

Diese Tabelle gibt einen Überblick über die Käufe und Verkäufe (in Stück Aktien) pro Jahr und die daraus resultierenden Portfoliostände (in Stück Aktien), jeweils zum 01.01. sowie 31.12. der einzelnen Stichprobenjahre, berechnet aus den 5650 Kauf- und Verkaufsmeldungen von 1048 Insidern. Die rechten beiden Spalten geben die Portfoliowerte (in $€$, bewertet zu Anschaffungskosten), und den kumulierten Wert an verkauften Aktien im Untersuchungszeitraum an

\subsection{Analyse der Portfoliostände und Kaufverhalten der Insider in Zusammenhang mit dem Bestandsschutz}

Wie in Abschn. 4.3. dargestellt, konnten 72,35\% der Kaufmeldungen und 62,75\% der Verkaufsmeldungen kein korrespondierender Verkauf bzw Kauf zugeordnet werden, weshalb diese Meldungen in weiterer Folge bei der Analyse der identifizierten Insidergeschäfte nicht berücksichtigt wurden. Dennoch stellen auch die Kauf- und Verkaufsmeldungen, die nicht zu einem Geschäft kombiniert werden konnten, eine wertvolle Information für die Untersuchung dar, da sie Auskunft über den Portfoliostand der Insider geben können und damit der Wert des potentiell zum Verkauf stehenden Aktienvermögens der Insider gemessen werden kann. Im Rahmen dieses Kapitels wird daher nicht auf die identifizierten Insidergeschäfte abgestellt, sondern eine Analyse aller 5650 Kauf- und Verkaufsmeldungen der 1048 Insider im Zeitraum 01.07.2002 bis 30.06.2014 durchgeführt.

In einem ersten Schritt wird dazu für jeden Insider und jedes Insiderunternehmen der Stand des Portfolios sowie der Wert des Portfolios jeweils zum 31.12. der Jahre in der Stichprobe ermittelt. Tab. 3 gibt einen Überblick über die Entwicklung der Portfoliostände und Portfoliowerte der Insider über die einzelnen Stichprobenjahre.

Eine Analyse der Portfoliostände und -werte zeigt, dass sowohl die Anzahl an Aktien als auch der Wert der Aktienportfolios der Insider im Zeitablauf einen steigenden Verlauf aufweist. Ausnahmen bilden dazu die Jahre 2011 und 2012, in denen sowohl die Anzahl an Aktien als auch der Wert der Aktienportfolios rückläufig ist, was auf eine hohe Verkaufstätigkeit in diesen beiden Jahren schließen lässt. Am Ende 
des Untersuchungszeitraumes wurden von den 1048 Insidern rund 24,8 Mio. Stück Aktien mit einem Portfoliowert (zu Anschaffungskosten) von rund 589,4 Mio. $€$ gehalten.

Den rund 24,8 Mio. Stück gehaltenen Aktien am Ende des Untersuchungszeitraumes stehen Veräußerungen von rund 20,6 Mio. Stück Aktien im Untersuchungszeitraum gegenüber. Damit wurden von den Insidern im Untersuchungszeitraum insgesamt rund 45,4 Mio. Stück Aktien erworben, von denen rund 45,47\% im Untersuchungszeitraum wieder veräußert wurden. Um einen Vergleich zwischen dem Wert der veräußerten und nicht veräußerten Aktien pro Insider durchführen zu können, wird der kumulierte Wert der veräußerten Aktien im Untersuchungszeitraum (bewertet zu Anschaffungskosten) dem Wert der nicht veräußerten Aktien (ebenfalls bewertet zu Anschaffungskosten) gegenübergestellt. Insgesamt wurden im Untersuchungszeitraum Verkäufe im Wert von rund 697,6 Mio. $€$ durchgeführt. Dem stehen rund 589,4 Mio. $€$ Aktienvermögen am Ende des Untersuchungszeitraumes gegenüber, womit im Untersuchungszeitraum insgesamt Vermögen mit Anschaffungskosten von über 1,29 Mrd. $€$ von den Insidern erworben wurde. 54,21\% des insgesamt erworbenen Vermögens wurde von den Insidern im Untersuchungszeitraum veräußert.

Zusammenfassend lässt sich festhalten, dass nur für 383 der 1048 beobachteten Insider Insidergeschäfte identifiziert werden konnten. Zudem zeigt die Auswertung der Portfoliostände und -werte der Insider, dass rund die Hälfte der Portfoliowerte im Untersuchungszeitraum nicht veräußert wurde. Es ist daher anzunehmen, dass viele Insider in der Stichprobe langfristig orientiert, dh an einem langfristigen Vermögensaufbau oder an strategischen Zielen interessiert sind. Die identifizierten Geschäfte und beobachteten Haltedauern beziehen sich hingegen auch auf kurzfristig orientierte Insider, weshalb bei der Analyse von Haltedauern nur für diese Gruppe von Insidern Aussagen zur Steuersensitivität getroffen werden können. Dem ist jedoch entgegenzuhalten, dass langfristig orientierte Insider unter dem Halbeinkünfteverfahren aufgrund der kurzen Spekulationsfrist von einem Jahr ohnehin vermutlich ganz überwiegend steuerfrei veräußert haben und somit der Wegfall der Spekulationsfrist für diese Insidergruppe nicht relevant gewesen sein dürfte.

Eine weitere Analyse, für die alle 3400 gemeldeten Käufe der 1048 Insider herangezogen werden, befasst sich mit der Frage des Kaufverhaltens der Insider in Zusammenhang mit dem Bestandsschutz. Dieser gilt für Wertpapiere, die vor 2009 angeschafft wurden, sodass bei ihrer Veräußerung noch die bis 2008 geltende Rechtslage zur Anwendung kommt (siehe Abschn. 2.2). Es ist davon auszugehen, dass steuersensitive Insider noch vor In-Kraft-Treten der Steuerreform vermehrt Aktieninvestitionen tätigen, um im Falle der Veräußerung nach einer Haltedauer von mehr als einem Jahr weiterhin von der Steuerfreiheit zu profitieren. Eichfelder und Lau (2014) zeigen, dass am deutschen Aktienmarkt signifikant abnormale Handelsvolumina für die letzten Handelstage des Jahres 2008 festgestellt werden können und führen dies darauf zurück, dass Investoren von der letztmaligen Möglichkeit Gebrauch machten, Aktien unter der alten Rechtslage mit Bestandsschutz $\mathrm{zu}$ erwerben. ${ }^{24}$

${ }^{24}$ Vgl. Eichfelder und Lau (2014), S. $14 \mathrm{ff}$. 
Tab. 4 Anzahl an gekauften Aktien im 4. Quartal, 2002-2013

\begin{tabular}{llllll}
\hline Jahr & Oktober & November & Dezember & $\begin{array}{l}\text { 4. Quartal } \\
\text { gesamt }\end{array}$ & $\begin{array}{l}\text { In \% } \\
\text { von 2008 }\end{array}$ \\
\hline 2002 & 200.089 & 263.503 & 105.316 & 568.908 & 14,93 \\
2003 & 59.332 & 69.220 & 80.960 & 209.512 & 5,50 \\
2004 & 3061 & 16.100 & 12.568 & 31.729 & 0,83 \\
2005 & 50 & 149.144 & 310.961 & 460.355 & 12,08 \\
2006 & 31.774 & 553.793 & 616.964 & 1.202 .531 & 31,57 \\
2007 & 41.145 & 148.635 & 259.439 & 449.219 & 11,79 \\
2008 & 1.735 .343 & 1.264 .970 & 809.332 & 3.809 .645 & 100,00 \\
2009 & 79.261 & 17.000 & 13.769 & 110.030 & 2,89 \\
2010 & 37.389 & 478.707 & 388.202 & 904.298 & 23,74 \\
2011 & 63.415 & 211.427 & 155.718 & 430.560 & 11,30 \\
2012 & 8500 & 158.454 & 246.919 & 413.873 & 10,86 \\
2013 & 6160 & 398.136 & 106.600 & 510.896 & 13,41 \\
\hline
\end{tabular}

Diese Tabelle gibt einen Überblick über die Anzahl an gekauften Aktien in den Monaten Oktober, November und Dezember sowie für das gesamte 4. Quartal der Jahre 2002 bis 2013. Die rechte Spalte gibt das Verhältnis der gesamten Anzahl an gekauften Aktien im 4. Quartal des jeweiligen Jahres zur Anzahl an gekauften Aktien im 4. Quartal des Jahres 2008, unmittelbar vor Einführung der Abgeltungssteuer, an

In Anlehnung an Eichfelder und Lau (2014) wird untersucht, ob auch unter den Insidermeldungen ein Anstieg an Käufen kurz vor dem Jahreswechsel 2008/2009 und damit eine Steuersensitivität der Insider beobachtet werden kann. Dafür werden alle 3400 Kaufmeldungen (siehe Abschn. 4.3.), unabhängig davon, ob diesen ein späterer Verkauf zugewiesen werden konnte, dem jeweiligen Kaufmonat zugeordnet und die Anzahl an gekauften Aktien pro Monat der Stichprobe berechnet. Tab. 4 gibt einen Überblick über die Anzahl der getätigten Käufe jeweils für das letzte Quartal der Jahre 2002 bis 2013.

Tab. 4 zeigt, dass im letzten Quartal des Jahres 2008 ein deutlicher Anstieg an gekauften Aktien beobachtet werden kann. Insgesamt wurden in den drei letzten Monaten des Jahres 2008 über 3,8 Mio. Stück Aktien von Insidern gekauft - dieser Wert ist mehr als dreimal so hoch wie der Wert in 2006, dem Jahr mit dem zweithöchsten Wert in der Stichprobe und über 34-mal so hoch wie der Wert des Folgejahres 2009. Es erscheint daher plausibel, dass Insider unmittelbar vor InKraft-Treten der Steuerreform vermehrt Aktien gekauft haben, um in den Genuss des Bestandsschutzes zu kommen.

Um sicherzugehen, dass durch die vermehrten Käufe im letzten Quartal 2008 keine systematische Beeinflussung der geschätzten Haltedauern stattfindet, wird zusätzlich untersucht, wie hoch die Anzahl der im letzten Quartal 2008 gekauften und am Ende des Untersuchungszeitraumes am 30.06.2014 noch nicht veräußerten Aktien ist. Zum 30.06.2014 wurden von den Insidern noch 1.921.318 Stück Aktien, die im letzten Quartal 2008 erworben wurden, gehalten, was einer Verkaufsquote von rund 50,4\% entspricht. Diese unterscheidet sich nicht wesentlich von der allgemeinen Verkaufsquote von 45,47\%, berechnet aus den Werten in Tab. 3, weshalb eine systematische Beeinflussung der gemessenen Haltedauern oder eine Verschiebung 
von lang- und kurzfristigen Investitionen durch den Bestandsschutz unwahrscheinlich ist.

\section{Untersuchung der Haltedauern von Insidergeschäften}

\subsection{Untersuchungshypothesen}

Vor Einführung der Abgeltungssteuer war es aus steuerlicher Sicht sinnvoll, Aktienverkäufe erst nach Ablauf der einjährigen Spekulationsfrist zu tätigen, um steuerfrei veräußern zu können. Seit der Abschaffung dieser Frist mit Beginn des Jahres 2009 haben kurzfristige Veräußerungsgewinne keinen steuerlichen Nachteil mehr. Geht man davon aus, dass die Wahl des Verkaufsdatums durch die Insider von steuerlichen Motiven beeinflusst ist, kann folgende Hypothese formuliert werden:

Hypothese 1 Durch die Einführung der Abgeltungssteuer kann eine Verringerung der Haltedauer bei Insidergeschäften beobachtet werden.

Wie in Abschn. 2.2. erwähnt, wurde mit der Einführung der Abgeltungssteuer auch die Möglichkeit zur Verlustverrechnung in Zusammenhang mit Aktienverkäufen geändert. Unter dem Halbeinkünfteverfahren konnten Veräußerungsverluste nur mit Veräußerungsgewinnen verrechnet werden, sofern sie innerhalb der einjährigen Spekulationsfrist anfielen. Da Veräußerungsgewinne aus unwesentlichen Beteiligungen mit einer Haltedauer von mehr als einem Jahr nicht besteuert wurden, waren auch Verluste außerhalb der Spekulationsfrist steuerlich weder ausgleichs- noch abzugsfähig. Im Halbeinkünfteverfahren bestand deshalb ein Anreiz zur Realisation von Verlusten innerhalb der Spekulationsfrist. Dieser Anreiz blieb von der Möglichkeit eines einkunftsartspezifischen Vor- oder Rücktrags von Veräußerungsverlusten unberührt. Unter der Abgeltungssteuer hingegen werden sämtliche Veräußerungsgewinne besteuert. Daher sind auch sämtliche realisierten Veräußerungsverluste mit Veräußerungsgewinnen der gleichen oder einer späteren Periode verrechenbar. Der Anreiz, Veräußerungsverluste vor Ablauf der Spekulationsfrist zu realisieren, um sie steuerlich geltend zu machen, entfällt damit mit der Einführung der Abgeltungssteuer. Daraus wird folgende Hypothese formuliert:

Hypothese 2 Durch die Einführung der Abgeltungssteuer kann für Insidergeschäfte, bei denen ein Veräußerungsverlust realisiert wird, eine Verlängerung der Haltedauer beobachtet werden.

\subsection{Untersuchungsdesign}

Um zu testen, ob es einen signifikanten Unterschied der Haltedauern in den beiden Steuerperioden gibt, wird zunächst ein Zweistichproben-t-Test durchgeführt, um die Gleichheit der Mittelwerte zu testen. ${ }^{25}$

\footnotetext{
25 Voraussetzung für die Anwendung eines t-Tests ist eine normalverteilte Stichprobe. Um sicherzugehen, dass eine Normalverteilung der Haltedauern in den beiden Steuersystemen vorliegt, wurde ein Shapiro-
} 
In einem weiteren Schritt wird eine Regressionsanalyse zur Ermittlung der Einflussfaktoren der Haltedauer durchgeführt. Dazu wird folgende Regressionsgleichung geschätzt:

$$
\begin{aligned}
& \text { Haltedauer }_{i, j, t}=\alpha+\beta_{1} \cdot \text { Abgeltung }_{i, j, t}+\beta_{2} \cdot \text { Verlust }_{i, j, t}+ \\
& \beta_{3} \cdot \text { Abgeltung }_{i, j, t} \cdot \text { Verlust }_{i, j, t}+\beta \cdot X_{i, j, t}^{\prime}+\gamma_{i}+\lambda_{j}+\delta_{t}+\varepsilon_{i, j, t}
\end{aligned}
$$

Die abhängige Variable, Haltedauer ${ }_{i, j, t}$, gibt die ermittelte Haltedauer eines Insidergeschäftes für Unternehmen $i$, Insider $j$ und Jahr $t$ in Tagen an. Um festzustellen, ob die Einführung der Abgeltungssteuer zu einer signifikanten Veränderung der Haltedauer geführt hat, wird die Indikatorvariable Abgeltung $g_{i, j, t}$ in die Regressionsgleichung aufgenommen. Diese nimmt für alle Veräußerungsvorgänge unter der Abgeltungssteuer den Wert 1 und sonst 0 an. In Übereinstimmung mit Hypothese 1 wird ein negativer Koeffizient für die Variable Abgeltung $_{i, j, t}$ erwartet. Verlust $t_{i, j, \mathrm{t}}$ ist eine weitere Indikatorvariable, die für Veräußerungsgeschäfte, bei denen ein Veräußerungsverlust realisiert wurde, den Wert 1 und sonst 0 annimmt. Zur Überprüfung von Hypothese 2 dient der Interaktionskoeffizient Abgeltung $_{i, j, t} \cdot \operatorname{Verlust}_{i, j, t}$, für den ein positives Vorzeichen erwartet wird.

Der Effekt der Steuerreform auf die Haltedauer der Insidergeschäfte wird über einen Zeitraumdummy, Abgeltun $g_{i, j, t}$, gemessen. Diese Dummyvariable bildet somit nicht nur die steuerlichen Effekte ab, sondern auch andere zeitliche Effekte, die im Untersuchungszeitraum eine Rolle gespielt haben. Denkbare andere Effekte, wie $\mathrm{zB}$ eine Veränderung in der erfolgsabhängigen Entlohnung der Insider oder Effekte durch die Finanzkrise, können aufgrund des Zeitraumdummies nicht von steuerlichen Effekten getrennt werden. Um eine Isolierung des steuerlichen Effektes durchführen zu können, wäre die Verwendung einer Kontrollgruppe, die keinen steuerlichen Effekten ausgesetzt ist, die ideale Vorgehensweise. Leider ist die Bildung einer Kontrollgruppe, wie in Abschn. 4.1. bereits erwähnt, in diesem Setting nicht möglich. Es wird daher in Abschn. 5.5. anhand diverser Sensitivitätsanalysen versucht, die Stichprobe unterschiedlich einzuschränken, sodass andere zeitliche Effekte, die neben den steuerlichen Effekten auftreten, bestmöglich eliminiert werden können.

Neben diesen drei Steuervariablen fließen weitere nichtsteuerliche Kontrollvariablen auf Insiderebene, $X^{\prime}{ }_{i, j, t}$, in das Regressionsmodell ein. ${ }^{26}$ Zur Berücksichtigung von unternehmensfixen, insiderfixen und jahresfixen Effekten werden die Indikatorvariablen $\gamma_{i}, \lambda_{j}$ und $\delta_{t}$ in das Modell integriert.

\footnotetext{
Wilk-Test durchgeführt, welcher zeigt, dass eine Normalverteilung der Daten vorliegt. Zusätzlich zum t-Test wurde ein Wilcoxon-Rangsummentest durchgeführt, da diesem Test keine Annahme hinsichtlich der Verteilung der Stichprobe zu Grunde liegt. Da die Ergebnisse des Wilcoxon-Rangsummentests mit jenen des t-Tests für alle durchgeführten Untersuchungen in Richtung und Signifikanz übereinstimmen, wird auf die Präsentation der Ergebnisse des Wilcoxon-Rangsummentests verzichtet.

26 Sämtliche nichtsteuerlichen Kontrollvariablen wurden ebenfalls aus der Datenbank der BaFin entnommen, weshalb sich die Auswahl an Kontrollvariablen auf die dort verfügbaren Daten beschränkt und zB eine Auswertung des Alters, steuerlichen Einkommens oder Durchschnittssteuersatzes der Insider nicht möglich ist.
} 
Die 1986 von Seyhun begründete Informations-Hierarchie-Hypothese besagt, dass unterschiedliche Insidergruppen über unterschiedlich wertvolle Informationen des Unternehmens verfügen und sich daher in ihrem Handelsverhalten unterscheiden (1986). Eine Vielzahl empirischer Studien zu Insidergeschäften, darunter Lin und Howe (1990) und Fidrmuc et al. (2006), verwendet daher Dummyvariablen, um Effekte für einzelne Insidergruppen zu separieren. In Anlehnung an diese Untersuchungen kontrollieren die Indikatorvariablen Vorstand $_{i, j, t}$, Aufsichtsrat ${ }_{i, j, t}$, Führung Fi,j, $_{\text {. }}$ (sonstige Führungspersonen) und sonstige $e_{i, j}$ (nahestehende Personen) für unterschiedliches Verhalten der einzelnen Insidergruppen; Veräußerungsgeschäfte von Vorstandsmitgliedern bilden hierzu die Referenzvariable. Da in das Modell jedoch auch Insiderfixeffekte aufgenommen werden, geben die Koeffizienten dieser Variablen nur den Unterschied in der Haltedauer für Insider, die in mehreren Positionen tätig sind, wieder.

Wie in Abschn. 4.3. erwähnt wurde und in Tab. 11 im Anhang ersichtlich ist, muss im Rahmen der Identifikation der Insidergeschäfte häufig eine Aufspaltung einer Verkaufsmeldung auf mehrere Teilverkäufe durchgeführt werden, um dem FIFO-Prinzip Rechnung zu tragen. Dies führt dazu, dass ein Verkauf in mehrere kleine Teilverkäufe aufgeteilt wird und es entsprechend zu einer höheren Anzahl an identifizierten Geschäften pro Insider als gemeldeter Verkäufe pro Insider kommt. Damit wird Geschäften mit geringer Stückzahl das gleiche Gewicht zugewiesen wie Geschäften mit hoher Stückzahl. Die so entstehenden Größeneffekte können nicht vermieden werden, da Teilverkäufe aufgrund des FIFO-Prinzips unterschiedliche Haltedauern aufweisen und daher nicht zusammengefasst werden können. Frühere Untersuchungen zu Insidergeschäften, die ebenfalls auf Größeneffekte kontrollieren, sind Rau (2004), Dymke und Walter (2008), Betzer und Theissen (2009) und Dardas und Güttler (2011). Um für Größeneffekte zu kontrollieren, wird die Variable Volume $_{i, j, t}$ als nichtsteuerliche Kontrollvariable im Modell verwendet. Volumen $_{i, j, t}$ ist definiert als der Verkaufserlös (verkaufte Stückzahl an Aktien (in Tsd Stück) multipliziert mit dem entsprechenden Verkaufspreis).

Alternativ zur Basisspezifikation wird eine weitere Regressionsgleichung geschätzt, die ebenfalls für Größeneffekte kontrolliert, indem die unterschiedliche Höhe der realisierten Veräußerungsgewinne bzw -verluste einfließt. Dazu werden sowohl die absolute Höhe des ermittelten Veräußerungsgewinnes bzw -verlustes (in Tsd $€$ ) sowie die Interaktion der beiden Werte mit der Indikatorvariable Abgeltung $_{i, j, t}$ in das Modell aufgenommen:

$$
\begin{aligned}
& \text { Haltedauer }_{i, j, t}=\alpha+\beta_{1} \cdot \text { Abgeltung }_{i, j, t}+\beta_{2} \cdot \text { absVerlust }_{i, j, t}+ \\
& \beta_{3} \cdot \text { Abgeltung }_{i, j, t} \cdot \text { absVerlust }_{i, j, t}+\beta_{4} \cdot \text { absGewinn }_{i, j, t}+ \\
& \beta_{5} \cdot \text { Abgeltung }_{i, j, t} \cdot \text { absGewinn }_{i, j, t}+\beta \cdot X_{i, j, t}^{\prime}+\gamma_{i}+\lambda_{j}+\delta_{t}+\varepsilon_{i, j, t}
\end{aligned}
$$

Unter der Annahme effizienter Kapitalmärkte und positiver erwarteter Wertentwicklung führen längere Haltedauern zu höheren Veräußerungsgewinnen bzw -verlusten. Zudem ist anzunehmen, dass steuerplanerische Aktivitäten und somit auch der Lock-in-Effekt mit der Höhe des erwarteten Veräußerungsgewinnes (bzw -verlustes) steigen. In Übereinstimmung mit den Hypothesen 1 und 2 werden demnach ein negativer Koeffizient für die Interaktionsvariable 
Tab. 5 Verteilung der Haltedauern unter den beiden Steuersystemen

\begin{tabular}{lllllll}
\hline & \multicolumn{2}{l}{ Alle Transaktionen } & \multicolumn{2}{l}{ Veräußerungsgewinn } & \multicolumn{2}{c}{ Veräußerungsverlust } \\
\hline Steuersystem & HEV & AS & HEV & AS & HEV & AS \\
$N$ & 922 & 289 & 754 & 228 & 168 & 61 \\
Mittelwert & 864,99 & 483,09 & 837,38 & 468,41 & 988,89 & 537,98 \\
Standardabweichung & 826,76 & 472,08 & 829,13 & 455,11 & 806,88 & 531,26 \\
Min & 0 & 0 & 0 & 0 & 0 & 0 \\
Max & 3774 & 1687 & 3774 & 1687 & 3528 & 1512 \\
Ergebnisse Zweistichproben-t-test & & & & & 4,054 & \\
t-Wert & 7,478 & & 6,431 & & 0,0000 & \\
$p>$ t & 0,0000 & & 0,0000 & & & \\
\hline
\end{tabular}

Diese Tabelle gibt einen Überblick über die Verteilung der Haltedauern (in Tagen) unter den beiden untersuchten Steuersystemen des Halbeinkünfteverfahrens (HEV) sowie der Abgeltungssteuer (AS) insgesamt und getrennt nach Geschäften, bei denen ein Veräußerungsgewinn und ein Veräußerungsverlust erzielt wurde. $N$ bezeichnet die Anzahl an beobachteten Geschäften pro Steuersystem. Die Verteilung der Haltedauern (in Tagen) wird anhand des arithmetischen Mittelwerts, der Standardabweichung sowie der minimalen und maximalen Haltedauer angegeben. Der untere Teil dieser Tabelle zeigt die Ergebnisse des Zweistichproben-t-Tests zur Überprüfung der Gleichheit der Haltedauern unter beiden Steuersystemen. Der t-Wert gibt das Ergebnis der Teststatistik und $p>t$ das dazugehörige Signifikanzniveau an

Abgeltung $_{i, j, t} \cdot$ Gewinn $_{i, j, t}$ sowie ein positiver Koeffizient für die Interaktionsvariable Abgeltung ${ }_{i, j, t} \cdot$ Verlust $_{i, j, t}$ erwartet.

\subsection{Deskriptive Statistik und Ergebnisse des nichtparametrischen Tests zur Verteilung der Haltedauern}

Tab. 5 gibt einen Überblick über die Verteilung der Haltedauern unter den beiden Steuersystemen $(\mathrm{HEV}=$ Halbeinkünfteverfahren, AS = Abgeltungssteuer) sowie die Ergebnisse des Zweistichproben-t-Tests.

Der Vergleich der Mittelwerte über alle Transaktionen zeigt einen deutlichen und signifikanten Rückgang der Haltedauer von rund 864 Tagen im Halbeinkünfteverfahren auf rund 483 Tage unter der Abgeltungssteuer. Im Mittel kann daher eine signifikante Reduktion der Haltedauer um rund 380 Tage beobachtet werden.

Die Auswertung der Haltedauern der Insidergeschäfte mit Veräußerungsgewinnen zeigt, dass die durchschnittliche Haltedauer im Halbeinkünfteverfahren mit 837 Tagen einerseits über der Spekulationsfrist von einem Jahr und andererseits auch deutlich über der durchschnittlichen Haltedauer unter der Abgeltungssteuer (468 Tage) liegt. Der durchgeführte Zweistichproben-t-Test auf Gleichheit der Mittelwerte in beiden Steuersystemen kann auf einem Signifikanzniveau von unter $1 \%$ abgelehnt werden. Die Haltedauer bei Insidergeschäften unter der Abgeltungssteuer ist somit signifikant niedriger als jene unter dem Halbeinkünfteverfahren.

Betrachtet man hingegen die Haltedauern der Insidergeschäfte mit Veräußerungsverlusten, so zeigt sich, dass steuerliche Aspekte der Verlustverrechnung in Zusammenhang mit Insidergeschäften offenbar keine ausschlaggebende Rolle spielen. Die durchschnittliche Haltedauer eines Verlustgeschäfts liegt im Halbeinkünfteverfahren mit 988 Tagen deutlich über der Spekulationsfrist und auch über der durchschnittlichen Haltedauer unter der Abgeltungssteuer. Verlustgeschäfte unter dem Halbein- 


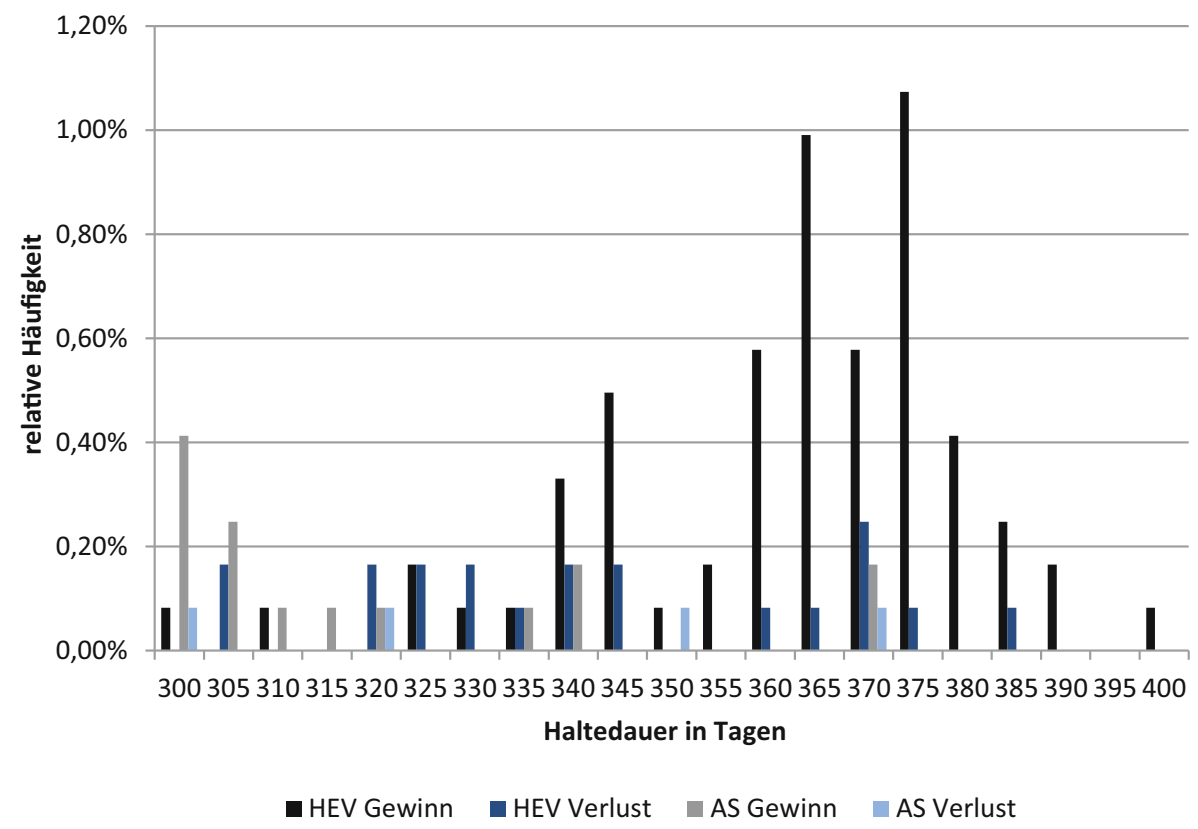

Abb. 2 Relative Häufigkeit der Haltedauern im Intervall [300;400] Tage. (Diese Abbildung zeigt die relative Häufigkeit der Haltedauern im Intervall von 300 bis 400 Tagen, zusammenfasst in Intervallen zu 5 Tagen. Die angezeigten Häufigkeiten werden einerseits nach dem Steuersystem und andererseits nach Gewinn- und Verlustgeschäften getrennt voneinander dargestellt. Erwartet wird eine Häufung von Realisationen bei Gewinngeschäften unter dem Halbeinkünfteverfahren unmittelbar nach Ende der Spekulationsfrist im Intervall [366; 380] Tage)

künfteverfahren weisen eine höhere durchschnittliche Haltedauer auf als Gewinngeschäfte. Es kann zwar auch bei Verlustgeschäften ein signifikanter Unterschied in den Mittelwerten der beiden Stichproben nachgewiesen werden, der aber entgegen den Erwartungen einen deutlichen Rückgang in den Haltedauern bei Verlustgeschäften unter der Abgeltungssteuer zeigt.

Vergleicht man die Haltedauern von Gewinn- und Verlustgeschäften innerhalb desselben Steuersystems, so zeigt sich, dass die Haltedauer von Gewinngeschäften im Halbeinkünfteverfahren signifikant niedriger ist als jene von Verlustgeschäften (auf einem Signifikanzniveau von 5\%), während unter der Abgeltungssteuer keine signifikante Differenz der Haltedauer von Gewinn- und Verlustgeschäften festgestellt werden kann.

Unter dem Halbeinkünfteverfahren führte die Möglichkeit zur steuerfreien Veräußerung von Aktien nach Ablauf der einjährigen Spekulationsfrist zu einem Lockin-Effekt, der sich durch eine Häufung der Realisierung von Veräußerungsgewinnen unmittelbar nach Überschreiten der Spekulationsfrist von 365 Tagen manifestieren sollte. Nachfolgende Grafik gibt einen Überblick über die relative Verteilung der Haltedauern unter den beiden Steuersystemen für Gewinn- und Verlustgeschäfte getrennt im Intervall [300; 400] Tage. 
Tab. 6 Anzahl der Verlustgeschäfte mit Haltedauern unter einem Jahr, 2002-2014

\begin{tabular}{llll}
\hline Jahr & $\begin{array}{l}\text { Anzahl Ver- } \\
\text { lustgeschäfte } \\
\text { insgesamt }\end{array}$ & $\begin{array}{l}\text { Verlustgeschäfte } \\
\text { mit Haltedauer } \\
<1 \text { Jahr }\end{array}$ & \% Anteil \\
\hline 2002 & 3 & 3 & 100,00 \\
2003 & 4 & 1 & 25,00 \\
2004 & 0 & 0 & 0,00 \\
2005 & 9 & 5 & 55,56 \\
2006 & 3 & 3 & 100,00 \\
2007 & 7 & 7 & 100,00 \\
2008 & 52 & 32 & 61,54 \\
2009 & 25 & 1 & 4,00 \\
2010 & 22 & 6 & 27,27 \\
2011 & 18 & 6 & 33,33 \\
2012 & 34 & 4 & 11,76 \\
2013 & 38 & 4 & 10,53 \\
2014 & 14 & 3 & 21,43 \\
Gesamt & 229 & 75 & 32,75 \\
\hline
\end{tabular}

Diese Tabelle gibt einen Überblick über die Anzahl der Verlustgeschäfte pro Untersuchungsjahr sowie über die Anzahl an Verlustgeschäften, die innerhalb der Spekulationsfrist von einem Jahr realisiert wurden und den prozentuellen Anteil der Verlustgeschäfte mit Haltedauern unter einem Jahr an den gesamten Verlustgeschäften eines Jahres

Wie aus Abb. 2 ersichtlich ist, kann unter dem Halbeinkünfteverfahren eine sehr hohe Anzahl an Transaktionen für Gewinngeschäfte mit einer Haltedauer knapp über der Spekulationsfrist von 365 Tagen beobachtet werden. Im Intervall [366; 380] Tage finden sich unter dem Halbeinkünfteverfahren 32 beobachtete Geschäfte (rund 2,64\% aller Geschäfte), während im selben Haltedauerintervall für Verlustgeschäfte unter dem Halbeinkünfteverfahren nur sechs Beobachtungen liegen und unter der Abgeltungssteuer nur drei Geschäfte (rund 0,33\% aller Geschäfte; davon zwei Gewinngeschäfte und ein Verlustgeschäft) beobachtet werden können. ${ }^{27}$ In keinem anderen 5-Tages-Intervall finden sich im Halbeinkünfteverfahren so viele Geschäfte wie dies zwischen 371 und 375 Tagen der Fall ist. Dies ist neben der bereits erwähnten geringeren Haltedauer unter der Abgeltungssteuer ein weiteres Zeichen dafür, dass Transaktionen unter dem Halbeinkünfteverfahren unmittelbar nach dem Ablauf der Spekulationsfrist getätigt wurden und steuerliche Lock-in-Effekte zu höheren Haltedauern geführt haben, als dies ohne Spekulationsfrist der Fall gewesen wäre.

Wie in Abschn. 2.2. erwähnt, konnten bis 31.12.2008 vorhandene Verlustvorträge aus privaten Veräußerungsgeschäften gemäß $§ 23$ Abs. 3 EStG mit späteren Veräußerungsgewinnen, die der Abgeltungssteuer unterlagen, verrechnet werden. Um von dieser Vortragsmöglichkeit zu profitieren, mussten verlustbringende Aktien innerhalb der Spekulationsfrist von einem Jahr und noch vor dem 31.12.2008 verkauft

\footnotetext{
27 Im Intervall [351; 365] Tage finden sich dagegen nur 11 Geschäfte, von denen 10 im Halbeinkünftever-
} fahren (ausschließlich Gewinngeschäfte) und 1 (Verlustgeschäft) unter der Abgeltungssteuer stattfanden. 
Tab. 7 Verteilung der Haltedauern für Geschäfte unter den beiden Steuersystemen nach Position des Insiders

\begin{tabular}{|c|c|c|c|c|c|c|c|c|}
\hline \multirow[b]{2}{*}{ Steuersystem } & \multicolumn{2}{|c|}{ Vorstand } & \multicolumn{2}{|c|}{ Aufsichtsrat } & \multicolumn{2}{|c|}{$\begin{array}{l}\text { Sonstige Füh- } \\
\text { rungsperson }\end{array}$} & \multicolumn{2}{|c|}{ Nahestehende Person } \\
\hline & $\mathrm{HEV}$ & AS & $\mathrm{HEV}$ & AS & HEV & AS & $\mathrm{HEV}$ & AS \\
\hline$N$ & 562 & 180 & 232 & 86 & 48 & 10 & 80 & 13 \\
\hline Mittelwert & 940,76 & 459,05 & 803,68 & 562,36 & 164,60 & 147,20 & 930,68 & 549,92 \\
\hline $\begin{array}{l}\text { Standard- } \\
\text { abweichung }\end{array}$ & 858,81 & 465,76 & 781,97 & 499,57 & 356,70 & 93,59 & 716,36 & 431,20 \\
\hline Min & 0 & 0 & 0 & 0 & 0 & 0 & 0 & 0 \\
\hline $\operatorname{Max}$ & 3768 & 1592 & 3774 & 1687 & 1590 & 277 & 3251 & 1190 \\
\hline \multicolumn{9}{|c|}{ Ergebnisse Zweistichproben-t-Test } \\
\hline $\mathrm{t}$-Wert & 7,191 & & 2,665 & & 0,151 & & 1,857 & \\
\hline$p>\mathrm{t}$ & 0,0000 & & 0,0081 & & 0,8803 & & 0,0665 & \\
\hline
\end{tabular}

Diese Tabelle gibt einen Überblick über die Verteilung der Haltedauern (in Tagen) unter den beiden untersuchten Steuersystemen des Halbeinkünfteverfahrens (HEV) sowie der Abgeltungssteuer (AS), getrennt nach den vier Insidergruppen Vorstand, Aufsichtsrat, sonstige Führungspersonen und nahestehende Personen. $N$ bezeichnet die Anzahl an beobachteten Geschäften pro Steuersystem und Insidergruppe. Die Verteilung der Haltedauern (in Tagen) wird anhand des arithmetischen Mittelwerts, der Standardabweichung sowie der minimalen und maximalen Haltedauer angegeben. Der untere Teil dieser Tabelle zeigt die Ergebnisse des Zweistichproben-t-Tests zur Überprüfung der Gleichheit der Haltedauern unter beiden Steuersystemen pro Insidergruppe. Der t-Wert gibt das Ergebnis der Teststatistik und $p>\mathrm{t}$ das dazugehörige Signifikanzniveau an

werden. Um zu überprüfen, ob Insider diese Möglichkeit bewusst genutzt haben, um verlustbringende Titel noch vor der Umstellung auf die Abgeltungssteuer zu veräußern, wird analysiert, wie hoch der Anteil an Verlustgeschäften, die innerhalb der Spekulationsfrist realisiert wurden, an den gesamten Verlustgeschäften eines Jahres ist. Obwohl die Spekulationsfrist mit der Umstellung auf die Abgeltungssteuer abgeschafft wurde, werden die Werte auch für die Jahre ab 2009 berechnet. Tab. 6 gibt einen Überblick über die Anzahl der Verlustgeschäfte pro Untersuchungsjahr sowie über die Anzahl an Verlustgeschäften, die innerhalb der Spekulationsfrist von einem Jahr realisiert wurden.

Die Werte in Tab. 6 zeigen, dass im Jahr 2008 die höchste Anzahl an Geschäften mit Verlusten beobachtet werden kann und alleine dieses Jahr für fast ein Viertel aller beobachteten Verlustgeschäfte verantwortlich ist. In Hinblick auf den Ausbruch der Finanzkrise in diesem Zeitraum kann der Einfluss der Umstellung auf die Abgeltungssteuer schwer separiert werden. Auffallend ist jedoch, dass im Jahr 2008 auch ein sehr hoher Anteil an Verlustgeschäften mit einer Haltedauer unter einem Jahr identifiziert wurde, der sich in den folgenden Jahren, trotz fortdauernder Finanzkrise, nicht fortsetzt. Dieses Ergebnis zeigt daher, dass Insider kurz vor der Umstellung auf die Abgeltungssteuer vermehrt kurzfristige gehaltene, verlustbringende Titel veräußert haben und diese Veräußerungsverluste steuerlich vortragsfähig waren.

Tab. 7 gibt einen Überblick über die Verteilung der Haltedauern unter den beiden Steuersystemen nach Position des Insiders getrennt. Die Unterscheidung nach Position des Insiders basiert auf der in Abschn. 5.2. erläuterten Information Hierarchy Hypothesis. 
Bereits der Vergleich der Mittelwerte der Haltedauern in Tab. 7 zeigt ein überraschendes Ergebnis: Während sich die Haltedauern von Mitgliedern des Vorstands, des Aufsichtsrates und nahestehender Personen in beiden Steuersystemen auf dem Niveau der Gesamtstichprobe bewegen, liegt die durchschnittliche Haltedauer für sonstige Führungspersonen in beiden Steuersystemen deutlich unter der Spekulationsfrist von einem Jahr. Zusätzlich zeigt der durchgeführte t-Test für sonstige Führungspersonen keinen signifikanten Unterschied in den mittleren Haltedauern.

Beurteilt man die Veränderung der Haltedauer der einzelnen Insidergruppen, so kann lediglich für Geschäfte von Vorstandsmitgliedern und Aufsichtsratsmitgliedern ein hoch signifikanter Unterschied in den mittleren Haltedauern nachgewiesen werden. Einschränkend anzumerken ist jedoch, dass für die anderen zwei Gruppen teilweise sehr geringe Stichprobenumfänge vorliegen und vor allem die Anzahl der Beobachtungen unter der Abgeltungssteuer sehr gering ausfällt.

Interessengegensätze im Sinne von Principal-Agent-Problemen dürften vor allem zwischen Anteilseignern und Vorstandsmitgliedern auftreten. Im Sinne einer anreizkompatiblen Entlohnung, die auf eine Harmonisierung von Anteilseigner- und Managementinteressen durch langfristige Beteiligung des Managements am Aktienkapital abzielt, ist die starke Verringerung der durchschnittlichen Haltedauer von Vorstandsmitgliedern als dysfunktionaler Effekt der Abgeltungssteuer anzusehen.

\subsection{Ergebnisse der Regressionsanalyse}

Zur genaueren Ermittlung der Einflussfaktoren auf die Haltedauern werden im weiteren Schritt die Regressionsgleichungen aus Abschn. 5.2. geschätzt. Tab. 8 gibt einen Überblick über die Ergebnisse der Schätzungen.

Wie aus Tab. 8 ersichtlich ist, liegt für alle Schätzungen eine signifikant niedrigere Haltedauer unter der Abgeltungssteuer vor. Spezifikation (2) unterteilt die untersuchten Geschäfte in Gewinn- und Verlustgeschäfte. Hier ist erkennbar, dass zwar für Gewinngeschäfte eine signifikante Reduktion der Haltedauer stattfindet, zugleich jedoch keine signifikante Erhöhung der Haltedauer bei Verlustgeschäften beobachtet werden kann. Der Koeffizient von Abgeltung $_{i, j, t} \cdot \operatorname{Verlust}_{i, j, t}$ ist insignifikant und weist auch ein unerwartetes Vorzeichen auf. Eine mögliche Erklärung

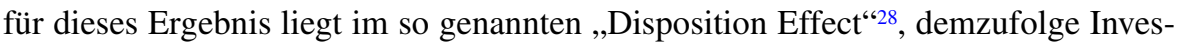
toren dazu tendieren, verlustträchtige Aktien zu spät zu verkaufen. Die Ursache für diesen Effekt wird in verhaltensökonomischen Theorien begründet; so konnten unter anderem Shefrin und Statman (1985) und Ferris et al. (1987) zeigen, dass Investoren Verluste nicht realisieren, da sie davon ausgehen, dass der Aktienkurs in der Zukunft doch wieder steigen könnte oder dass Verluste nicht realisiert werden, da man sich sonst eingestehen müsste, eine falsche Entscheidung beim Kauf der Aktien getroffen zu haben. Bei Insidern könnte zudem der Verkauf von Aktien des eigenen Unternehmens als ungünstiges Indiz für die Einschätzung des Arbeitserfolges interpretiert werden.

In den Spezifikationen (2) bis (5) wird für den Insidertyp kontrolliert, wobei in Spezifikation (2a) zusätzlich Interaktionseffekte mit dem Zeitraum der Ab-

28 Vgl. Odean (1998), S. 1775. 
Tab. 8 Ergebnisse der Regressionsanalysen

\begin{tabular}{|c|c|c|c|c|c|c|}
\hline Spezifikation & $\begin{array}{l}(1) \\
\text { OLS }\end{array}$ & $\begin{array}{l}(2) \\
\text { OLS }\end{array}$ & $\begin{array}{l}\text { (2a) } \\
\text { OLS }\end{array}$ & $\begin{array}{l}(3) \\
\text { OLS }\end{array}$ & $\begin{array}{l}(4) \\
\text { OLS }\end{array}$ & $\begin{array}{l}(5) \\
\text { Poisson }\end{array}$ \\
\hline Abgeltung & $\begin{array}{l}-381,89 * * * \\
(90,26)\end{array}$ & $\begin{array}{l}-629,77 * * * \\
(132,76)\end{array}$ & $\begin{array}{l}-766,30 * * * \\
(164,55)\end{array}$ & $\begin{array}{l}-909,49 * * * \\
(154,16)\end{array}$ & $\begin{array}{l}-562,53 * * * \\
(122,69)\end{array}$ & $\begin{array}{l}-0,8665^{* * * *} \\
(0,1498)\end{array}$ \\
\hline Verlust & - & $\begin{array}{l}-9,24 \\
(96,99)\end{array}$ & $\begin{array}{l}-9,75 \\
(96,25)\end{array}$ & $\begin{array}{l}-30,43 \\
(93,96)\end{array}$ & - & $\begin{array}{l}-0,0292 \\
(0,0942)\end{array}$ \\
\hline $\begin{array}{l}\text { Abgeltung } \\
\text { Verlust }\end{array}$ & - & $\begin{array}{l}-35,98 \\
(158,14)\end{array}$ & $\begin{array}{l}22,96 \\
(154,11)\end{array}$ & $\begin{array}{l}-40,33 \\
(162,09)\end{array}$ & - & $\begin{array}{l}-0,1469 \\
(0,2103)\end{array}$ \\
\hline Aufsichtsrat & - & $\begin{array}{l}205,23 \\
(184,65)\end{array}$ & $\begin{array}{l}12,64 \\
(165,56)\end{array}$ & $\begin{array}{l}15,01 \\
(238,91)\end{array}$ & $\begin{array}{l}175,92 \\
(181,65)\end{array}$ & $\begin{array}{l}0,3608 \\
(0,2919)\end{array}$ \\
\hline Führung & - & $\begin{array}{l}345,30 \\
(226,121)\end{array}$ & $\begin{array}{l}-0,0076 \\
(0,0087)\end{array}$ & $\begin{array}{l}41,77 \\
(101,61)\end{array}$ & $\begin{array}{l}306,18 \\
(201,66)\end{array}$ & $\begin{array}{l}0,4360 * * \\
(0,1890)\end{array}$ \\
\hline sonstige & - & $\begin{array}{l}-237,83 * \\
(143,32)\end{array}$ & $\begin{array}{l}-271,16 \\
(179,90)\end{array}$ & $\begin{array}{l}-155,82 * \\
(141,22)\end{array}$ & $\begin{array}{l}-281,04 * \\
(147,29)\end{array}$ & $\begin{array}{l}-0,8813^{* *} \\
(0,4093)\end{array}$ \\
\hline $\begin{array}{l}\text { Abgeltung · } \\
\text { Aufsichtsrat }\end{array}$ & - & - & $\begin{array}{l}503,12 * * \\
(218,17)\end{array}$ & - & - & - \\
\hline $\begin{array}{l}\text { Abgeltung · } \\
\text { Führung }\end{array}$ & - & - & $\begin{array}{l}673,70 * * * \\
(164,51)\end{array}$ & - & - & - \\
\hline $\begin{array}{l}\text { Abgeltung } \cdot \\
\text { sonstige }\end{array}$ & - & - & $\begin{array}{l}222,04 \\
(331,11)\end{array}$ & - & - & - \\
\hline Volumen & - & $\begin{array}{c}-0,0044 \\
(0,0060)\end{array}$ & $\begin{array}{l}0,0048 \\
(0,0055)\end{array}$ & $\begin{array}{c}-0,0024 \\
(0,0058)\end{array}$ & - & $\begin{array}{l}-0,0062 \\
(0,0047)\end{array}$ \\
\hline absVerlust & - & - & - & - & $\begin{array}{l}0,1268 \\
(0,3328)\end{array}$ & - \\
\hline absGewinn & - & - & - & - & $\begin{array}{l}- \\
0,0203 * * * \\
(0,0023)\end{array}$ & - \\
\hline $\begin{array}{l}\text { Abgeltung } \\
\text { absVerlust }\end{array}$ & - & - & - & - & $\begin{array}{l}-0,0121 \\
(0,3346)\end{array}$ & - \\
\hline $\begin{array}{l}\text { Abgeltung - } \\
\text { absGewinn }\end{array}$ & - & - & - & - & $\begin{array}{l}-0,2677 * * * \\
(0,1142)\end{array}$ & - \\
\hline
\end{tabular}

geltungssteuer aufgenommen werden. Die Verkürzung der Haltedauer unter der Abgeltungssteuer in Spezifikation (2a) bleibt dabei signifikant. Zusätzlich zeigt sich, dass die Reduktion der Haltedauer bei Aufsichtsratsmitgliedern und sonstigen Führungspersonen signifikant geringer ausfällt als bei Vorstandsmitgliedern. Dennoch ist, mit Ausnahme der nahestehenden Personen, für alle Gruppen von Insidern eine signifikante Reduktion der Haltedauer festzustellen, die für Gewinngeschäfte bei Vorstandsmitgliedern 766,30 Tage, bei Aufsichtsratsmitgliedern 263,18 Tage $(=766,30-503,12)$ und bei sonstigen Führungspersonen 92,60 Tage $(=766,30-673,70)$ beträgt.

Um sicherzugehen, dass insiderspezifische, unternehmensspezifische und zeitspezifische Faktoren keinen Einfluss auf die Ergebnisse haben, wird in den Spezifikationen (2) bis (5) zusätzlich für Insider-, Unternehmens- und Jahresfixeffekte ${ }^{29}$ kontrolliert; die Ergebnisse bleiben davon unberührt. Zusammenfassend kann festgehalten

29 Alternativ zu Jahresfixeffekten wurde Spezifikation (3) auch mit Monatsfixeffekten geschätzt, sodass für Korrelationen von Verkäufen desselben Monats kontrolliert werden kann. Der Koeffizient von Abgeltung 
Tab. 8 Ergebnisse der Regressionsanalysen (Fortsetzung)

\begin{tabular}{lllllll}
\hline Spezifikation & $(1)$ & $(2)$ & $(2 \mathrm{a})$ & $(3)$ & $(4)$ & $(5)$ \\
& OLS & OLS & OLS & OLS & OLS & Poisson \\
\hline Unter- & Nein & Ja & Ja & Ja & Ja & Ja \\
nehmensFE & - & - & - & - & - & - \\
InsiderFE & Nein & Ja & Ja & Ja & Ja & Ja \\
JahresFE & Nein & Nein & Nein & Ja & Nein & Nein \\
$N$ & 1211 & 1211 & 1211 & 1211 & 1211 & 1211 \\
$\mathrm{R}^{2}$ & 0,0442 & 0,8359 & 0,8400 & 0,8583 & 0,8428 & - \\
\hline
\end{tabular}

Diese Tabelle gibt die Ergebnisse der in Abschn. 5.2. beschriebenen Regressionsgleichungen wieder. In normaler Schreibweise ist der Wert des Koeffizienten vermerkt, in Klammern der Wert des robusten, auf Ebene des Insiders geclusterten Standardfehlers. Abgeltung ist eine Dummyvariable, die den Wert 1 annimmt, wenn ein Geschäft unter die Abgeltungssteuer fällt wird und 0 bei Geschäften unter dem Halbeinkünfteverfahren. Verlust ist eine Dummyvariable, die Geschäfte, bei denen ein Veräußerungsverlust erzielt wurde, mit 1 kennzeichnet. Aufsichtsrat, Führung und sonstige sind ein Set an Dummyvariablen, die die Position des Insiders angeben. In Spezifikationen, in denen Insidereffekte inkludiert sind, messen die Koeffizienten dieser Variablen nur noch Effekte für Insider, die Geschäfte in mehr als einer Funktion realisiert haben. In den Spezifikationen (1) bis (3) kontrolliert Volumen für Größeneffekte und wird gemessen als Verkaufserlös in Tsd €. Spezifikation (4) ist eine alternative Spezifikation zur Messung der Größeneffekte. Anstelle von Volumen wird die absolute Höhe des ermittelten Veräußerungsgewinnes, absGewinn, bzw -verlustes, absVerlust, in Tsd $€$, sowie die Interaktion dieser beiden Variablen mit Abgeltung in das Modell integriert. Die Variablen in Spezifikation (5) sind analog zu Spezifikation (3), jedoch wird aufgrund der nichtnegativen, ganzzahligen Ausprägung der Haltedauer ein Zähldatenmodell geschätzt. Für alle Spezifikationen wird angegeben, ob Fixeffekte auf Ebene des Insiders, des Unternehmens oder Zeitfixeffekte bei der Schätzung miteinbezogen wurden

*** geben ein Signifikanzniveau von $1 \%$, ** von $5 \%$ und * gibt ein Signifikanzniveau von $10 \%$ an

werden, dass die Ergebnisse der Regressionsanalyse Hypothese 1 unterstützen, während Hypothese 2 verworfen werden muss.

Spezifikation (4) in Tab. 8 gibt einen Überblick über die Ergebnisse der zweiten Regressionsgleichung aus Abschn. 5.2. Erneut kann eine signifikant niedrigere Haltedauer unter der Abgeltungssteuer nachgewiesen werden. ${ }^{30}$ Zudem zeigt sich, dass die Haltedauer sowohl mit der Höhe des Veräußerungsgewinnes als auch des Veräußerungsverlustes steigt; der Koeffizient für den absoluten Wert des Veräußerungsverlustes ist allerdings, wie auch der Koeffizient für die Interaktion mit der Zeitraumvariable, nicht signifikant. Für Gewinngeschäfte kann jedoch unter dem Halbeinkünfteverfahren eine signifikante Erhöhung der Haltedauer bei steigendem Veräußerungsgewinn festgestellt werden, während dieser Effekt unter der Abgeltungssteuer umgekehrt und signifikant ist.

Die beobachtete Haltedauer der Insidergeschäfte ist stets ein nichtnegativer und ganzzahliger Wert in Tagen. Um zu überprüfen, ob das in den Spezifikationen (1) bis (4) unterstellte lineare Regressionsmodell zur Schätzung des Einflusses des Steuersystems auf Haltedauern geeignet ist, wird zusätzlich ein Zähldatenmodell geschätzt.

weist in dieser Schätzung einen Wert von $-852,42$ auf (1\% Signifikanzniveau). Alle anderen Koeffizienten unterscheiden sich hinsichtlich Vorzeichen und Signifikanzen ebenfalls nicht.

30 Wenngleich in allen Spezifikationen in Tab. 8 für das Volumen der Transaktion als erklärende Variable kontrolliert wird, wird jeder Transaktion dasselbe Gewicht beigemessen. Alternativ werden die Spezifikationen (1) bis (4) daher zusätzlich als gewichtete Regressionen geschätzt, bei denen Volumen als Gewichtungsfaktor fungiert. Für alle Spezifikationen kann erneut ein auf dem $1 \%$ Signifikanzniveau negativer Koeffizient für Abgeltung festgestellt werden. 
Tab. 9 Ergebnisse der Sensitivitätsanalysen

\begin{tabular}{|c|c|c|c|c|c|}
\hline Sensitivitätsanalyse & (A) & (B) & (C) & (D) & (E) \\
\hline Abgeltung & $\begin{array}{l}-1476,92^{* * * *} \\
(297,16)\end{array}$ & $\begin{array}{l}-843,64 * * * \\
(164,11)\end{array}$ & $\begin{array}{l}-727,45 * * * \\
(148,46)\end{array}$ & $\begin{array}{l}-1003,18 * * * \\
(333,43)\end{array}$ & $\begin{array}{l}-560,91 * * * \\
(144,64)\end{array}$ \\
\hline Verlust & $\begin{array}{l}-227,36 \\
(278,59)\end{array}$ & $\begin{array}{l}-11,23 \\
(209,45)\end{array}$ & $\begin{array}{l}104,41 \\
(112,44)\end{array}$ & $\begin{array}{l}34,35 \\
(211,80)\end{array}$ & $\begin{array}{l}63,01 \\
(239,03)\end{array}$ \\
\hline $\begin{array}{l}\text { Abgeltung } \cdot \text { Ver- } \\
\text { lust }\end{array}$ & $\begin{array}{l}211,79 \\
(322,44)\end{array}$ & $\begin{array}{l}-24,46 \\
(99,81)\end{array}$ & $\begin{array}{l}-254,28 \\
(225,02)\end{array}$ & $\begin{array}{l}-1,01 \\
(426,93)\end{array}$ & $\begin{array}{l}-145,12 \\
(226,73)\end{array}$ \\
\hline Aufsichtsrat & $\begin{array}{l}-687,38 * \\
(353,38)\end{array}$ & $\begin{array}{l}11,30 \\
(209,45)\end{array}$ & $\begin{array}{l}784,80 * * \\
(346,51)\end{array}$ & $\begin{array}{l}-11,38 \\
(412,65)\end{array}$ & $\begin{array}{l}61,85 \\
(239,03)\end{array}$ \\
\hline Führung & $\begin{array}{l}-0,0065 \\
(0,0079)\end{array}$ & $\begin{array}{l}-35,90 \\
(106,04)\end{array}$ & $\begin{array}{l}269,60 \\
(267,51)\end{array}$ & $\begin{array}{l}-0,01 \\
(0,01)\end{array}$ & $\begin{array}{l}0,11 * * * \\
(0,03)\end{array}$ \\
\hline sonstige & $\begin{array}{l}587,73 \\
(216,12)\end{array}$ & $\begin{array}{l}-187,48 \\
(197,64)\end{array}$ & $\begin{array}{l}- \\
-\end{array}$ & $\begin{array}{l}-195,75 \\
(166,21)\end{array}$ & $\begin{array}{l}-519,97 * \\
(292,91)\end{array}$ \\
\hline Volumen & $\begin{array}{l}-0,0041 \\
(0,0050)\end{array}$ & $\begin{array}{l}-0,0063 \\
(0,0040)\end{array}$ & $\begin{array}{l}-0,0001 * \\
(0,0000)\end{array}$ & $\begin{array}{l}0,0003 \\
(0,0003)\end{array}$ & $\begin{array}{l}-0,0725 * * * \\
(0,0193)\end{array}$ \\
\hline InsiderFE & $\mathrm{Ja}$ & $\mathrm{Ja}$ & $\mathrm{Ja}$ & $\mathrm{Ja}$ & $\mathrm{Ja}$ \\
\hline UnternehmensFE & $\mathrm{Ja}$ & $\mathrm{Ja}$ & $\mathrm{Ja}$ & $\mathrm{Ja}$ & $\mathrm{Ja}$ \\
\hline ZeitFE & $\mathrm{Ja}$ & $\mathrm{Ja}$ & $\mathrm{Ja}$ & $\mathrm{Ja}$ & $\mathrm{Ja}$ \\
\hline$N$ & 708 & 1059 & 528 & 525 & 813 \\
\hline $\mathrm{R}^{2}$ & 0,8877 & 0,8479 & 0,8598 & 0,8924 & 0,8443 \\
\hline
\end{tabular}

Diese Tabelle gibt die Ergebnisse unterschiedlicher Sensitivitätsanalysen wieder. In normaler Schreibweise ist der Wert des Koeffizienten vermerkt, in Klammern der Wert des robusten, auf Ebene des Insiders geclusterten Standardfehlers. Die dargestellten Variablen entsprechen jenen der Basisspezifikationen in Tab. 8. Analyse A kontrolliert für die ungleiche zeitliche Verteilung der beiden Steuersysteme innerhalb der Stichprobe. Analyse B schließt Geschäfte, die vermutlich in Zusammenhang mit einer Optionsausübung stehen, aus. Analysen C und D kontrollieren für die Annahme, dass Insider zum Beginn der Untersuchung keinen Vorbesitz an Aktien hatten. Analyse E kontrolliert für Effekte aus den geänderten Vorschriften zur Meldepflicht ab 2005. Für alle Spezifikationen wird angegeben, ob Fixeffekte auf Ebene des Insiders, des Unternehmens oder Zeitfixeffekte bei der Schätzung einbezogen wurden

*** geben ein Signifikanzniveau von $1 \%$, ** von $5 \%$ und * gibt ein Signifikanzniveau von $10 \%$ an

Da der Mittelwert der Haltedauer in der Gesamtstichprobe annähernd gleich hoch ist wie die Standardabweichung (siehe Tab. 5) kann sowohl Über- als auch Unterstreuung der Daten ausgeschlossen werden und es wird ein Poisson-Modell zur Schätzung von Spezifikation (5) verwendet. Die Ergebnisse zeigen hinsichtlich des Vorzeichens und der Signifikanz der Koeffizienten keinen Unterschied zur OLSSchätzung in Spezifikation (3). Erneut zeigt sich eine signifikant niedrigere Haltedauer für Gewinngeschäfte unter der Abgeltungssteuer.

\subsection{Sensitivitätsanalysen}

Um sicherzugehen, dass die Ergebnisse in Abschn. 5.4. nicht durch bestimmte Annahmen bei der Stichprobengenerierung getrieben werden, wurden Sensitivitätsanalysen durchgeführt, deren Ergebnisse in Tab. 9 zusammengefasst sind.

Ein Problem in der Auswertung der Insidergeschäfte stellt die ungleiche zeitliche Verteilung der beiden Steuersysteme innerhalb der Stichprobe dar. Durch die Einführung der Abgeltungssteuer zum 01.01.2009 und den geltenden Bestandsschutz für davor erworbene Aktien kann die maximale Haltedauer unter der Abgeltungssteuer 
am Ende des Beobachtungszeitraumes am 30.06.2014 2006 Tage nicht überschreiten. Im Gegenzug finden sich in der Stichprobe 95 Insidergeschäfte unter dem Halbeinkünfteverfahren, deren Haltedauer über 2006 Tagen liegt. Um sicherzugehen, dass die Ergebnisse nicht durch die ungleiche zeitliche Verteilung der beiden Steuersysteme beeinflusst werden, wird folgende Modifikation der Stichprobe durchgeführt: Der Beobachtungszeitraum unter dem Halbeinkünfteverfahren wird jenem der Abgeltungssteuer angepasst, indem nur Verkäufe zwischen dem 01.07.2002 und dem 28.12.2007 berücksichtigt werden. Damit ist sichergestellt, dass die maximale Haltedauer unter dem Halbeinkünfteverfahren ebenfalls genau 2006 Tage betragen kann. Die so entstehende Teilstichprobe 1 umfasst 708 Insidergeschäfte, von denen nur noch $419(59,18 \%)$ dem Halbeinkünfteverfahren zugerechnet werden sowie alle 289 Geschäfte $(40,82 \%)$ unter der Abgeltungssteuer aus der Gesamtstichprobe. Die Auswertung von Teilstichprobe A zeigt, dass für Gewinngeschäfte auch im Falle einer identischen zeitlichen Länge der beiden Steuersysteme eine signifikante Reduktion der Haltedauern zu verzeichnen ist; für Verlustgeschäfte hingegen kann erneut keine signifikante Änderung in den Haltedauern festgestellt werden.

Von den 1211 identifizierten Insidergeschäften der Gesamtstichprobe weisen 152 eine Haltedauer von null Tagen auf, dh Kauf und Verkauf fanden am selben Tag statt. Eine nähere Analyse dieser Geschäfte zeigt, dass diese meist auf Kaufmeldungen basieren, denen die Ausübung einer Option zu Grunde liegt. Viele dieser Optionen werden ausgeübt und die erworbenen Aktien noch am selben Tag wieder veräußert. Bei diesen Insidergeschäften kann daher davon ausgegangen werden, dass nichtsteuerliche Faktoren einen größeren Einfluss auf die Haltedauer haben. Aus diesem Grund werden alle Geschäfte mit einer Haltedauer von null Tagen aus der Stichprobe eliminiert. ${ }^{31}$ Die so entstehende Teilstichprobe B umfasst 1059 Insidergeschäfte (827 Geschäfte unter dem Halbeinkünfteverfahren und 232 unter der Abgeltungssteuer). Dadurch steigt die durchschnittliche Haltedauer auf 964 Tage unter dem Halbeinkünfteverfahren bzw 601 Tage unter der Abgeltungssteuer an. Die Regressionsanalyse zeigt erneut, dass unter der Abgeltungssteuer eine signifikante Reduktion der Haltedauern für Gewinngeschäfte besteht und unterstützt die Ergebnisse der Gesamtstichprobe.

Wie in Abschn. 4.3. erwähnt, beruht die Identifikationsstrategie der Insidergeschäfte auf der Annahme, dass zu Beginn des Untersuchungszeitraumes am 01.07.2002 kein Vorbesitz an Aktien durch Insider gehalten wurde. Diese vereinfachende Annahme wird nicht in allen Fällen der Realität entsprechen und kann dazu führen, dass der rechnerische Aktienbestand eines Insiders im Laufe des

\footnotetext{
${ }^{31}$ Die Auswertung der Daten zeigt, dass viele Insider dazu tendieren, sämtliche Geschäfte in Zusammenhang mit Optionen zu melden, auch wenn diese nicht meldepflichtig sind. Um zu verhindern, dass Verzerrungen in den Daten dadurch entstehen, dass freiwillige Meldungen in Zusammenhang mit als Vergütungsbestandteilen erhaltenen Optionen in der Stichprobe enthalten sind, werden alle Beobachtungen, die aus Optionsausübungen stammen, aus der Stichprobe entfernt. Dabei handelt es sich einerseits um 130 Geschäfte mit einer Haltedauer von null Tagen (siehe Unterstichprobe B) sowie 22 weitere Geschäfte mit einer Haltedauer von einem Tag und mehr. Erneut zeigt sich eine signifikant niedrigere Haltedauer unter der Abgeltungssteuer, weshalb davon ausgegangen werden kann, dass die Berücksichtigung freiwillig gemeldeter Transaktionen in Zusammenhang mit Optionsausübungen keine Verzerrung der Stichprobe hervorruft.
} 
Beobachtungszeitraumes negativ wird, wodurch aus den vorhandenen Meldungen Geschäfte falsch identifiziert werden können. Um dieses Problem zu mildern, wird folgende Bereinigung der Stichprobe durchgeführt: Es wurde versucht, für alle 383 Insider zu ermitteln, wann sie in ihr Unternehmen eingetreten sind. Erfolgte der Eintritt vor dem 01.07.2002 (Beginn der Offenlegungspflicht), so kann ein Vorbesitz an Aktien nicht ausgeschlossen werden. Bei einem Eintritt nach Beginn der Meldepflicht besteht hingegen mit hoher Wahrscheinlichkeit kein Vorbesitz an Aktien. Jene 30 Insider, die als nahestehende Personen klassifiziert wurden, werden von dieser Sensitivitätsanalyse ausgeschlossen, da nicht ermittelt werden kann, ob die Definition der nahestehenden Person (siehe Abschn. 2.1.) bereits zu Beginn des Untersuchungszeitraumes erfüllt war. Von weiteren 62 Insidern konnte trotz Durchsicht der Geschäftsberichte, der Homepage des Unternehmens sowie diverser Suchmaschinen nicht ermittelt werden, wann sie in das Unternehmen eingetreten waren. Im Endergebnis konnte somit für 291 Insider ein Eintrittsdatum ermittelt werden, wobei 163 (56,01\%) erst ab dem 01.07.2002 ins Unternehmen eingetreten sind. In weiterer Folge wurden die in Abschn. 5.4. durchgeführten statistischen Auswertungen ausschließlich für die identifizierten Geschäfte dieser 163 Insider wiederholt, um zu zeigen, ob die Annahme eines nicht vorhandenen Vorbesitzes einen Einfluss auf die Ergebnisse hat.

Die Stichprobe C der Sensitivitätsanalyse umfasst insgesamt 528 identifizierte Geschäfte, von denen 354 (67,05\%) unter dem Halbeinkünfteverfahren und 174 $(32,95 \%)$ unter der Abgeltungssteuer realisiert wurden. Der gestiegene Anteil an Geschäften unter der Abgeltungssteuer kann durch den im Vergleich zur Gesamtstichprobe späteren Eintritt der Insider in das Unternehmen erklärt werden. Die Ergebnisse der Sensitivitätsanalyse zeigen, dass sich die Haltedauern aus der reduzierten Stichprobe nicht wesentlich von jenen der Gesamtstichprobe unterscheiden. Erneut finden sich unter der Abgeltungssteuer signifikant kürzere Haltedauern für Gewinngeschäfte. Zudem weisen in dieser Stichprobe Aufsichtsratsmitglieder im Vergleich zu den anderen Insidergruppen schwach signifikant höhere Haltedauern auf.

Sensitivitätsanalyse D widmet sich ebenfalls dem Problem, dass der von Insidern zum Stichtag 01.07.2002 gehaltene Vorbesitz an Aktien nicht beobachtet werden kann. Bei all jenen Insidern, deren Portfoliostand im Laufe des Beobachtungszeitraumes negativ wird, muss davon ausgegangen werden, dass entweder ein positiver Vorbesitz bestanden hat oder falsche Meldungen bzw Nichtmeldungen von Transaktionen vorliegen. Stichprobe D umfasst daher nur jene 525 Geschäfte von Insidern, für die über den gesamten Beobachtungszeitraum kein negativer Portfoliostand ermittelt wurde. Von den identifizierten Geschäften fanden 399 (76\%) unter dem Halbeinkünfteverfahren und $126(24 \%)$ unter der Abgeltungssteuer statt. Die prozentuelle Verteilung der Geschäfte auf die beiden Steuersysteme entspricht damit annähernd jener der Gesamtstichprobe. Die Ergebnisse der Sensitivitätsanalyse zeigen erneut signifikant niedrigere Haltedauern für Gewinngeschäfte unter der Abgeltungssteuer.

Wie in Abschn. 2.1. erwähnt, wurden die Meldepflichten für Insidergeschäfte durch das Anlegerschutzverbesserungsgesetz (AnSVG) zum 01.01.2005 verschärft und der Kreis der betroffenen Personen erweitert. Aus diesem Grund werden in Sensitivitätsanalyse E nur Transaktionen, die ab dem 01.01.2005 gemeldet wurden, zur Identifizierung von Insidergeschäften herangezogen. Zudem wird der Beobach- 
tungszeitraum auf die Perioden 01.01.2005 bis 31.12.2012 verkürzt, sodass für beide Steuersysteme jeweils genau vier Beobachtungsjahre vorliegen. Die neue Stichprobe umfasst 813 Insidergeschäfte von 262 Insidern, von denen 652 (80,20\%) dem Halbeinkünfteverfahren und $161(19,80 \%)$ der Abgeltungssteuer zugeordnet werden können. Die Ergebnisse zeigen, dass die Änderung der Meldepflicht durch das AnSVG keinen Einfluss auf die festgestellte signifikante Reduktion der Haltedauer unter der Abgeltungssteuer hat.

Wie in Abschn. 4.2. erwähnt, wird für die Ermittlung des steuerlichen Ergebnisses eines Geschäftes das FIFO-Prinzip angewandt. Dabei ist jedoch zu beachten, dass dieses nur auf Ebene des jeweiligen Depots angewandt werden kann und somit Insider die Möglichkeit hätten, durch die Eröffnung mehrerer Depots Steuerplanung zu betreiben, sodass am Ende anstelle des FIFO-Prinzips das LIFO- (Last in - First out) Prinzip zur Anwendung kommt. Zudem wäre denkbar, dass Insider Wertpapiere, die vor dem 01.01.2009 angeschafft wurden und Anschaffungen nach dem 01.01.2009 in getrennten Depots halten, um den für Anschaffungen vor dem 01.01.2009 geltenden Bestandsschutz möglichst lange nutzen zu können. Aus der Datenbank der BaFin kann nicht entnommen werden, ob ein Insider mehrere Depots besitzt bzw welchem Depot eine Meldung zugerechnet wird. Um Effekte, die durch die Aufteilung von Wertpapierkäufen auf mehrere Depots entstehen könnten, zu vermeiden, wird folgende Modifikation der Gesamtstichprobe durchgeführt: Ausgehend von Unterstichprobe D (Insider mit durchgehend positivem Portfoliostand) werden nur alle jene Insider berücksichtigt, die im Beobachtungszeitraum genau einen Kauf und Verkauf gemeldet haben. Dadurch kann unterstellt werden, dass diese Insider auch nur über ein Wertpapierdepot verfügen. Durch diese restriktive Annahme sinkt die Anzahl an beobachteten Geschäften jedoch auf 47 (Unterstichprobe F), von denen $38(80,85 \%)$ unter dem Halbeinkünfteverfahren und $9(19,14 \%)$ unter der Abgeltungssteuer stattgefunden haben. Da einerseits eine klare Richtung für die Entwicklung der Haltedauer erwartet wird (kürzere Haltedauern unter der Abgeltungssteuer) und nur eine geringe Anzahl an Beobachtungen vorliegt, werden die Haltedauern mittels eines einseitigen Zweistichproben-t-Tests ausgewertet. Die Hypothese, dass die Haltedauer unter beiden Steuersystemen im Mittelwert gleich hoch ist, wird dabei auf einem $10 \%$-Signifikanzniveau verworfen. ${ }^{32}$ Die Vermutung, dass die Ergebnisse durch die steueroptimale Aufteilung der Wertpapierkäufe auf mehrere Depots getrieben werden, findet daher keine Unterstützung.

Die Pflicht zur Meldung von Transaktionen mit Aktien eines Unternehmens entfällt, sobald ein Insider ein Unternehmen verlässt. Unter der Annahme, dass die globale Finanz- und Wirtschaftskrise zu einer Verkürzung der Beschäftigungsdauer von Insidern führte, könnte es sein, dass die Reduktion der Haltedauern unter der Abgeltungssteuer durch die kürzere Verweildauer im Unternehmen und nicht durch steuerliche Motive getrieben ist. Für die 112 Insider, für die Geschäfte unter der Abgeltungssteuer identifiziert werden konnten, wurde daher überprüft, wann die letzte Meldung in der Datenbank der BaFin vorliegt. Für 93 Insider (83,03\%)

\footnotetext{
32 Alternativ wurde auch ein zweiseitiger Zweistichproben-t-Test durchgeführt, bei dem die Hypothese, dass die Haltedauer unter beiden Steuersystemen im Mittelwert gleich hoch ist, allerdings nur auf einem $20 \%$-Signifikanzniveau verworfen werden kann.
} 
fand die letzte Meldung im Jahr 2013 oder später statt, weshalb davon ausgegangen werden kann, dass für die in der Stichprobe enthaltenen Insider keine krisenbedingt verkürzten Verweildauern im Unternehmen angenommen werden müssen.

\subsection{Verweildauermodell}

Den empirischen Auswertungen in den Abschn. 5.1. bis 5.5. liegen die Daten über die Haltedauer der 1211 identifizierten Insidergeschäfte (=Käufe und zurechenbare Verkäufe) zu Grunde. Von den insgesamt zur Verfügung stehenden 3400 Kaufmeldungen konnten, wie in Abschn. 4.3. dargestellt, 2460 Kaufmeldungen keinem Verkauf zugeordnet werden, weshalb diese in den Analysen der Abschn. 5.1. bis 5.5. nicht berücksichtigt werden konnten. Wenngleich für diese 2460 Kaufmeldungen keine Haltedauer ermittelt werden kann, da im Beobachtungszeitraum keine zuordenbare Veräußerung vorlag, kann eine Aussage über die Mindesthaltedauer getroffen werden. Zudem besteht die Möglichkeit, ein Verweildauermodell zu schätzen, in dem neben den realisierten Geschäften auch die gekauften, aber im Beobachtungszeitraum nicht wieder veräußerten Aktienbesitze berücksichtigt werden können. Insgesamt umfasst das Verweildauermodell Beobachtungen zu 3671 Käufen im Zeitraum 01.07.2002 bis 30.06.2014. Da 2460 Kaufmeldungen kein Verkauf und 940 Kaufmeldungen insgesamt 1211 Verkäufe zugeordnet werden konnten (vgl. Abschn. 4.3.), übersteigt die Anzahl der Beobachtungen (3671) die Anzahl der Kaufmeldungen (3400). Die maximal beobachtbare Haltedauer beträgt 4382 Tage bei einem Kauf unmittelbar am 01.07.2002 ohne Veräußerung im Beobachtungszeitraum.

Der Datensatz für das Verweildauermodell ist gekennzeichnet durch Rechts-Zensierung, da für den überwiegenden Teil der Käufe kein Verkauf beobachtet werden kann. Zugleich werden nicht alle Käufe bereits am ersten Tag des Untersuchungszeitraumes getätigt, weshalb der Datensatz zusätzlich linkszensiert ist. Für beide Zensierungen kann im Verweildauermodell kontrolliert werden.

$\mathrm{Zu}$ beachten ist, dass mittels Verweildauermodell zwar eine Aussage über die Wahrscheinlichkeit für einen Verkauf unter den beiden Steuersystemen getroffen werden kann, jedoch keine Aussage über die Veränderung in der Haltedauer der Geschäfte. Es ist anzunehmen, dass die erwartete kürzere Haltedauer unter der Abgeltungssteuer zu einer höheren Wahrscheinlichkeit für einen Verkauf unter der Abgeltungssteuer führt.

Ein Einfluss der Abgeltungssteuer ist darüber hinaus lediglich für Insider zu erwarten, die grundsätzlich handelsbereit sind. Insider, die - beispielsweise aufgrund dienstvertraglicher Verpflichtungen - ohnehin ein langfristiges Halten ihrer Aktien beabsichtigen, dürften auf die Einführung der Abgeltungssteuer nicht reagieren. Während die bisherigen Analysen ausschließlich abgeschlossene Transaktionen und somit handelsaktive Investoren behandelten, erfasst ein Verweildauermodell sowohl handelsaktive als auch langfristig orientierte Insider. Deshalb sind von einem Verweildauermodell tendenziell weniger stark ausgeprägte Effekte der Abgeltungssteuer zu erwarten.

Folgendes Verweildauermodell wird zur Modellierung der Wahrscheinlichkeit für einen Verkauf geschätzt: 
Tab. 10 Ergebnisse der Verweildauermodelle

\begin{tabular}{lllllll}
\hline \multicolumn{2}{l}{ Verweildauermodell (1) Cox } & $\begin{array}{l}\text { (1) Wei- } \\
\text { bull }\end{array}$ & (2) Cox & $\begin{array}{l}\text { (2) Wei- } \\
\text { bull }\end{array}$ & (3) Cox & $\begin{array}{l}\text { (3) Wei- } \\
\text { bull }\end{array}$ \\
\hline Abgeltung & 1,1014 & 1,0329 & $0,6927^{* *}$ & $0,7528^{*}$ & 1,0213 & $1,2821^{* * *}$ \\
& $(0,1488)$ & $(0,1331)$ & $(0,1134)$ & $(0,1184)$ & $(0,1169)$ & $(0,1084)$ \\
Aufsichtsrat & 0,8776 & 0,8816 & 1,0185 & 0,9953 & 0,9631 & $0,8549^{*}$ \\
& $(0,1326)$ & $(0,1290)$ & $(0,1952)$ & $(0,1812)$ & $(0,1243)$ & $(0,0766)$ \\
Führung & $1,6965^{* *}$ & $1,7687^{* *}$ & $2,0616^{* *}$ & $2,1647 * *$ & 1,4512 & 1,1534 \\
& $(0,446)$ & $(0,4725)$ & $(0,6497)$ & $(0,6944)$ & $(0,4098)$ & $(0,2151)$ \\
sonstige & 0,7156 & 0,7091 & 0,7619 & 0,7808 & 1,2555 & 1,0421 \\
& $(0,1739)$ & $(0,1591)$ & $(0,968)$ & $(0,1813)$ & $(0,2745)$ & $(0,1639)$ \\
Volumen & $1,0001 * *$ & $1,0001^{* * *}$ & 1,0000 & 1,0001 & $0,9999 * *$ & 0,9999 \\
& $(0,0000)$ & $(0,0000)$ & $(0,0000)$ & $(0,0000)$ & $(0,0000)$ & $(0,0000)$ \\
UnternehmensFE & $\mathrm{Ja}$ & $\mathrm{Ja}$ & $\mathrm{Ja}$ & $\mathrm{Ja}$ & $\mathrm{Ja}$ & $\mathrm{Ja}$ \\
$N$ & 3671 & 3671 & 2722 & 2722 & 1115 & 1115 \\
Time at risk & 5.365 .589 & 5.365 .589 & 1.982 .850 & 1.982 .850 & 1.027 .764 & 1.027 .764 \\
Verkauf & 1211 & 1211 & 708 & 708 & 708 & 708 \\
\hline
\end{tabular}

Diese Tabelle gibt die Ergebnisse der Verweildauermodelle wieder. In normaler Schreibweise ist der Wert der Hazard rate vermerkt, in Klammern der Wert des robusten, auf Ebene des Insiders geclusterten Standardfehlers. Die Variablen entsprechen jenen der Basisspezifikationen in Tab. 8. Analyse 1 berücksichtigt alle 3671 Kaufmeldungen im gesamten Untersuchungszeitraum. Analyse 2 kontrolliert für die ungleiche zeitliche Verteilung der beiden Steuersysteme innerhalb der Stichprobe. Analyse 3 berücksichtigt zusätzlich zu Analyse 2 ausschließlich Kaufmeldungen von handelsaktiven Insidern. Für alle Spezifikationen wird angegeben, ob Fixeffekte auf Ebene des Unternehmens bei der Schätzung einbezogen wurden *** geben ein Signifikanzniveau von $1 \%$, ** von $5 \%$ und * gibt ein Signifikanzniveau von $10 \%$ an

$$
\operatorname{Verkauf}_{i, j, t}=\beta_{1} \cdot \text { Abgeltung }_{i, j, t}+\beta \cdot X_{i, j, t}+\lambda_{j}+\varepsilon_{i, j, t}
$$

Verkauf $f_{i, j, t}$ ist eine Indikatorvariable, die am Tag des Verkaufs den Wert 1 annimmt. Um festzustellen, ob unter der Abgeltungssteuer signifikant häufiger verkauft wird, wird die Indikatorvariable Abgeltung $g_{i, j, t}$ in die Regressionsgleichung aufgenommen. Diese nimmt für alle Veräußerungsvorgänge unter der Abgeltungssteuer den Wert 1 und sonst 0 an. Es wird ein positiver Koeffizient für die Variable Abgeltung $_{i, j, t}$ erwartet. Neben dieser Steuervariablen fließen weitere nichtsteuerliche Kontrollvariablen auf Insiderebene, $X^{\prime}{ }_{i, j, t}$, (siehe Abschn. 5.2.) in das Regressionsmodell ein. ${ }^{33}$ Zur Berücksichtigung von unternehmensfixen Effekten wird die Indikatorvariable $\lambda_{j}$ in das Modell integriert.

Für jede Spezifikation des Verweildauermodells wird einerseits ein semiparametrisches Modell mit proportionalen Hazard rates (Cox-Modell) geschätzt, sowie ein parametrisches Modell (Weibull-Modell ${ }^{34}$ ). Tab. 10 gibt einen Überblick über die Ergebnisse des Verweildauermodells.

\footnotetext{
33 Sämtliche nichtsteuerlichen Kontrollvariablen wurden ebenfalls aus der Datenbank der BaFin entnommen, weshalb sich die Auswahl an Kontrollvariablen auf die dort verfügbaren Daten beschränkt und zB eine Auswertung des Alters, steuerlichen Einkommens oder Durchschnittssteuersatzes der Insider nicht möglich ist.

34 Zur Ermittlung des geeigneten parametrischen Modells werden folgende Modelle an Hand des AkaikeInformationskriteriums miteinander verglichen: Exponentiell, Weibull, Gompertz, Lognormal, Loglogis-
} 
Die beiden Spezifikationen (1) berücksichtigen sämtliche verfügbaren Kaufmeldungen und zeigen eine positive, aber nicht signifikante Hazard rate für Abgeltung. Ein Problem der Verwendung sämtlicher verfügbarer Kaufmeldungen besteht erneut in der ungleichen zeitlichen Verteilung der beiden Stichproben, da die maximale Haltedauer für Käufe unter dem Halbeinkünfteverfahren (4382 Tage) mehr als doppelt so hoch ist wie die maximale Haltedauer unter der Abgeltungssteuer (2006 Tage). Käufe unter dem Halbeinkünfteverfahren, die im Beobachtungszeitraum nicht veräußert werden, weisen im Schnitt eine mehr als doppelt so hohe Mindesthaltedauer auf, die jedoch ausschließlich auf die ungleiche Verteilung der beiden Zeiträume zurückzuführen ist.

Zur Vermeidung des Problems der ungleichen Verteilung der beiden Zeiträume wird in den beiden Spezifikationen (2) und (3) analog zu Sensitivitätsanalyse A aus Tab. 9 vorgegangen. Dabei wird unter dem Halbeinkünfteverfahren ausschließlich der Zeitraum 01.01.2002 bis 28.12.2007 berücksichtigt, sodass die maximale Haltedauer in beiden Systemen bei 2006 Tagen liegt. Von den verbleibenden 2722 Kaufmeldungen können 708 Verkäufe identifiziert werden, während 2014 Käufe im Beobachtungszeitraum nicht veräußert wurden. Von den 708 Verkäufen fallen 419 in den Zeitraum des Halbeinkünfteverfahrens (59,18\%) und 289 (40,82\%) in den Zeitraum der Abgeltungssteuer. Im Gegensatz dazu sind die Käufe, denen kein Verkauf zugeordnet werden kann, in beiden Steuersystemen annähernd gleich verteilt (986 Käufe unter dem Halbeinkünfteverfahren, 48,95\% versus 1028 Käufe unter der Abgeltungssteuer, 51,05\%). Der Anteil der Käufe, denen kein Verkauf zugeordnet werden kann, steigt von 67,34\% unter dem Halbeinkünfteverfahren auf 78,14\% unter der Abgeltungssteuer, was auf einen erhöhten Anteil langfristig orientierter Insider unter der Abgeltungssteuer schließen lässt.

Das Ergebnis zeigt einen signifikant negativen Koeffizienten für Abgeltung und damit eine signifikant höhere Wahrscheinlichkeit für eine Veräußerung unter dem Halbeinkünfteverfahren. Dieses Ergebnis wäre - im Gegensatz zu unserer Hypothese 1 - konsistent mit einer verlängerten Haltedauer unter der Abgeltungssteuer. Der erhöhte Anteil langfristig orientierter Insider könnte eine mögliche Erklärung für diesen Effekt sein.

In einem weiteren Verweildauermodell werden in Spezifikation (3) ausschließlich Käufe von handelsaktiven Insidern betrachtet. Als handelsaktiv werden Insider definiert, die im Beobachtungszeitraum aus Spezifikation (2) zumindest eine Veräußerung getätigt haben. Damit sollen jene Insider ausgeschlossen werden, die auf Grund einer langfristigen Orientierung generell keine Aktien veräußern und somit als nicht steuersensitiv eingestuft werden können. Von den ursprünglich 924 Insidern aus Spezifikation (2) werden 273 als handelsaktiv klassifiziert. Das WeibullModell zeigt für diese Gruppe eine signifikant positive Hazard rate von 1,2821. Die Wahrscheinlichkeit für einen Verkauf liegt damit für handelsaktive Insider unter der Abgeltungssteuer um rund 28,21\% höher als unter dem Halbeinkünfteverfahren.

Die Verweildauermodelle weisen folglich differenzierte Ergebnisse auf. Spezifikation (3) mit ausschließlich handelsaktiven Insidern unterstützt die Resultate unse-

tisch und Generalisiertes Gamma. Für alle Spezifikationen deutet das Akaike-Informationskriterium auf das Weibull-Modell als das bevorzugte Modell hin. 
rer zuvor durchgeführten Haltedaueranalysen, da die positive Hazard rate konsistent mit einer verkürzten Haltedauer unter der Abgeltungssteuer ist. Demgegenüber deutet Spezifikation (2), in der neben den handelsaktiven nun auch die - zahlreicheren - inaktiven Insider enthalten sind, mit dem signifikant negativen Koeffizienten für Abgeltung darauf hin, dass der Anteil der langfristig orientierten Insider nach Einführung der Abgeltungssteuer gestiegen ist.

\section{Zusammenfassung}

Seit Juli 2002 müssen Insider (Mitglieder des Leitungs-, Verwaltungs- oder Aufsichtsorgans, persönlich haftende Gesellschafter, sonstige Führungspersonen sowie nahestehende Personen) für Geschäfte mit Aktien ihres Unternehmens eine verpflichtende Meldung an die BaFin übermitteln, aus der unter anderem die Art der Transaktion (Kauf oder Verkauf) sowie die Stückzahl und der Kurs hervorgehen. Die so übermittelten Daten ermöglichen es, Insidergeschäfte auf individueller Basis zu identifizieren und daraus Haltedauern und die Höhe des realisierten Veräußerungsgewinnes bzw -verlustes zu berechnen.

Der vorliegende Beitrag verwendet erstmals Daten aus Insidergeschäften zur empirischen Bearbeitung einer steuerlichen Fragestellung, indem analysiert wird, ob durch die Einführung der Abgeltungssteuer eine Verringerung der Haltedauer für Gewinngeschäfte bzw eine Erhöhung der Haltedauer für Verlustgeschäfte stattgefunden hat. Mit dieser Untersuchung kann der bislang ungeklärten Forschungsfrage nachgegangen werden, inwieweit die Spekulationsfrist und ihre Abschaffung die Haltedauer von Aktien beeinflussen, was für die Schätzung des Steueraufkommens relevant sein kann.

Basierend auf einer Stichprobe von 1211 Insidergeschäften (922 davon aus dem Halbeinkünfteverfahren und 289 aus der Abgeltungssteuer) wird gezeigt, dass die Haltedauer für Gewinngeschäfte unter der Abgeltungssteuer wie erwartet signifikant niedriger ausfällt. Dieses Ergebnis bleibt auch bestehen, wenn für die unterschiedliche zeitliche Verteilung der beiden Steuersysteme kontrolliert wird oder Verkäufe aus der Ausübung von Aktienoptionen ausgeschlossen werden.

Zwar steht die Forschungsfrage nach den allgemeinen Haltedauerwirkungen der Veräußerungsgewinnbesteuerung im Mittelpunkt unserer Analyse, jedoch zeigt die Auswertung von Insiderdaten auch Corporate-Governance-spezifische Steuerwirkungen. ${ }^{35}$ Unter der Annahme, dass eine Interessenharmonisierung von Anteilseignern und Management durch eine möglichst langfristige Beteiligung des Managements am Aktienkapital der Unternehmung herbeigeführt wird, erschwert eine Veräußerungsgewinnbesteuerung, die zur Verkürzung von Haltedauern führt, eine anreizkompatible Entlohnung. Dies gilt insbesondere für die erhebliche Verringerung der durchschnittlichen Haltedauern von Vorstandsmitgliedern.

Im Gegensatz zu Gewinngeschäften kann eine steuerlich motivierte Wahl des Veräußerungszeitpunktes für Verlustgeschäfte verworfen werden, da entgegen der

\footnotetext{
${ }^{35} \mathrm{Zu}$ Corporate-Governance-Aspekten des Insiderhandels vgl. auch Betzer und Theissen (2009), die auch
} die Eigentümerstruktur der Unternehmen berücksichtigen. 
Hypothese eine Verringerung der durchschnittlichen Haltedauer auch bei Verlustgeschäften beobachtet wurde.

Obwohl sich die durchschnittlichen Haltedauern nach 2008 signifikant verringerten, kann ein Einfluss der Abgeltungssteuer auf die Insiderhandelsintensität nicht nachgewiesen werden. Würde Insiderhandel insgesamt als unerwünscht angesehen, wäre nicht der Abbau, sondern die Verschärfung des Lock-in-Effekts anzustreben. Im Sinne dieses denkbaren Ziels hätte lediglich die Spekulationsfrist ausgedehnt werden müssen. Überlegungen zum Insiderhandel dürften aber bei der Einführung der Abgeltungssteuer keine Rolle gespielt haben. ${ }^{36}$

Trotz der für eine steuerliche Untersuchung außergewöhnlich günstigen Datensituation unterliegt auch diese Studie Beschränkungen der Aussagekraft. Der Einfluss des Steuersystems auf die Haltedauern kann nur über einen Zeitraumdummy gemessen werden, sodass nichtsteuerliche Faktoren, die ebenfalls einen Einfluss auf die Haltedauer von Aktiengeschäften haben, nicht von den gleichzeitig auftretenden steuerlichen Faktoren getrennt werden können. Dieses Problem könnte nur durch den Vergleich mit einer Kontrollgruppe, die keinen steuerlichen Änderungen im Beobachtungszeitraum unterliegt, vermieden werden. Leider ist aus den verfügbaren Daten die Bildung einer Kontrollgruppe nicht möglich, weshalb durch umfassende Sensitivitätsanalysen versucht wurde, nichtsteuerliche Faktoren weitestgehend auszuschließen.

Bei den hier analysierten Insidern dürfte es sich um einen Personenkreis mit einem überdurchschnittlich hohen ökonomischen Ausbildungsstand handeln. Die Antizipation steuerlicher Folgen im Vorfeld von finanziellen Entscheidungen ist daher für Insider weitaus häufiger zu erwarten als im Durchschnitt aller Steuerpflichtigen. ${ }^{37}$ Die in dieser Untersuchung vorgestellten Haltedauereffekte dürften deshalb die durchschnittliche Reaktion von Steuerpflichtigen auf Rechtsänderungen tendenziell überzeichnen. Das gleiche Ergebnis einer überdurchschnittlichen Steuersensitivität von Insidern ist zusätzlich zu erwarten, weil Mitglieder von Vorständen und Aufsichtsräten von Aktiengesellschaften typischerweise dem Spitzensteuersatz der Einkommensteuer unterliegen. Der entgegengesetzte Effekt einer geringeren Steuersensitivität von Insidern könnte vorliegen, weil vom Führungspersonal von Aktiengesellschaften entweder implizit oder durch dienstvertragliche Regelungen eine langfristige Bindung an ihre Gesellschaft und damit eine geringe Verkaufsneigung erwartet werden könnte. Diese grundsätzliche Haltung dürfte durch Steuerreformen nur geringfügig beeinflusst werden.

Unsere empirischen Studien liefern Indizien für die parallele Existenz unterschiedlicher Grade der Steuersensitivität. Die Verkürzung der Haltedauern wird durch ein Verweildauermodell mit handelsaktiven Insidern unterstützt. Eine andere Spezifikation des Verweildauermodells mit allen, dh handelsaktiven und -inaktiven Insidern, bestätigt dieses Ergebnis nicht, sondern zeigt eine verringerte Veräußerungswahrscheinlichkeit unter der Abgeltungssteuer.

Diese Befunde deuten darauf hin, dass sich der Personenkreis der Insider aus einer (kleineren) steuersensitiven, handelsaktiven Gruppe und einer (größeren) lang-

\footnotetext{
36 Vgl. Deutscher Bundestag (2007).

37 Vgl. für experimentelle Studien mit deutschen Teilnehmern zB Blaufus et al. (2015).
} 
fristig orientierten, nicht handelsaktiven und damit weniger steuersensitiven Gruppe zusammensetzt, wobei letztere unter der Abgeltungssteuer noch gewachsen sein könnte.

Eine datenbedingte Einschränkung unserer Ergebnisse ist darin zu sehen, dass die Offenlegungspflicht für Insider nur für Geschäfte mit Wertpapieren ,ihres“ Unternehmens gilt. Eventuelle Portfolioeffekte wie die Verrechnung von Gewinnen und Verlusten aus Veräußerungsgeschäften mit anderen Wertpapieren können deshalb nicht beobachtet werden. Ähnliches gilt für die denkbare Duplikation von Aktienrückflüssen durch Derivate. Hierin könnte ein Grund für die unerwartete Haltedauerverkürzung bei Verlustgeschäften zu sehen sein.

Grundsätzlich wäre denkbar, dass steuerinduzierte Haltedaueränderungen die Effizienz der Preisbildung am Aktienmarkt beeinflussen. Sofern ein ausgeprägter steuerbedingter Lock-in-Effekt Insider daran hinderte, private Informationen unmittelbar in Handelsgewinne umzusetzen, würde der Wegfall des Lock-in-Effekts zu einem rascheren Einfließen der Insiderinformationen in die Preisbildung führen. Dieses Ergebnis könnte sich jedoch dadurch abschwächen, dass der Wegfall des Lock-inEffekts zugleich eine Verringerung des Insideranteils am Aktienkapital bewirkt. Auf der Grundlage unseres Modells ist der Nachweis derartiger steuerlicher Effekte nicht möglich; ${ }^{38}$ er erscheint jedoch angesichts durchschnittlicher Haltedauern auch nach Einführung der Abgeltungssteuer von mehr als einem Jahr eher unwahrscheinlich.

Angesichts des Steuergeheimnisses, das die Verfügbarkeit originär steuerlicher Daten in Deutschland erheblich einschränkt, ${ }^{39}$ bietet die Auswertung von Directors' Dealings eine vielversprechende Datenquelle, mit der die empirische Betriebswirtschaftliche Steuerlehre noch deutlich weitergehende Untersuchungen über die Wirkung von Steuern auf individuelle Anlageentscheidungen durchführen kann. Weiterführende Forschungsfragen sind beispielsweise die Einbeziehung individueller Investorenmerkmale sowie internationale Vergleiche von Insidertransaktionen. Darüber hinaus können durch Auswertung von Directors' Dealings Rückschlüsse auf die Zusammensetzung erfolgsabhängiger Entlohnungsverträge und den Steuereinfluss darauf gezogen werden.

Open access funding provided by University of Graz.

Open Access Dieser Artikel wird unter der Creative Commons Namensnennung 4.0 International Lizenz (http://creativecommons.org/licenses/by/4.0/deed.de) veröffentlicht, welche die Nutzung, Vervielfältigung, Bearbeitung, Verbreitung und Wiedergabe in jeglichem Medium und Format erlaubt, sofern Sie den/die ursprünglichen Autor(en) und die Quelle ordnungsgemäß nennen, einen Link zur Creative Commons Lizenz beifügen und angeben, ob Änderungen vorgenommen wurden.

\footnotetext{
38 Typischerweise werden die Marktreaktionen auf insiderbezogene Meldungen sowie Überrenditen von Insidern anhand von Ereignisstudien ermittelt. Vgl. zB Dymke und Walter (2008) und die dort genannten Quellen.

39 Da Steuerdaten in Schweden öffentlich verfügbar sind, bieten sich Transaktionen schwedischer Vorstands- und Aufsichtsratsmitglieder für eine Replikationsstudie an. Für die Verwendung schwedischer Steuerdaten vgl. zB Jacob und Alstadsater (2013 und 2015).
} 


\section{Anhang}

Folgende Tabelle zeigt anhand eines Beispiels die im Beitrag angewandte Vorgehensweise zur Identifikation von Insidergeschäften:

Tab. 11 Beispiel zur Identifikation von Insidergeschäften

\begin{tabular}{|c|c|c|c|c|c|c|c|}
\hline & Emittent & Geschäftsart & Handelstag & Nominale & Insider & $\begin{array}{l}\text { Haltedauer } \\
\text { (Tage) }\end{array}$ & $\begin{array}{l}\text { Geschäfts- } \\
\text { nummer }\end{array}$ \\
\hline 1 & $\begin{array}{l}\text { Continental } \\
\text { AG }\end{array}$ & $\mathrm{K}$ & 04.11 .2003 & 2000 & $\begin{array}{l}\text { H.-J. Ni- } \\
\text { kolin }\end{array}$ & - & 1 \\
\hline 2 & $\begin{array}{l}\text { Continental } \\
\text { AG }\end{array}$ & $\mathrm{V}$ & 04.11 .2003 & 2000 & $\begin{array}{l}\text { H.-J. Ni- } \\
\text { kolin }\end{array}$ & 0 & 1 \\
\hline 3 & $\begin{array}{l}\text { Continental } \\
\text { AG }\end{array}$ & K & 10.11 .2003 & 6000 & $\begin{array}{l}\text { H.-J. Ni- } \\
\text { kolin }\end{array}$ & - & 2 \\
\hline 4 & $\begin{array}{l}\text { Continental } \\
\mathrm{AG}\end{array}$ & $\mathrm{K}$ & 10.11 .2003 & 12.000 & $\begin{array}{l}\text { H.-J. Ni- } \\
\text { kolin }\end{array}$ & - & 3,4 \\
\hline 5 & $\begin{array}{l}\text { Continental } \\
\mathrm{AG}\end{array}$ & $\mathrm{K}$ & 10.11 .2003 & 18.000 & $\begin{array}{l}\text { H.-J. Ni- } \\
\text { kolin }\end{array}$ & - & 5,6 \\
\hline 6 & $\begin{array}{l}\text { Continental } \\
\text { AG }\end{array}$ & $\mathrm{K}$ & 24.08.2004 & 6000 & $\begin{array}{l}\text { H.-J. Ni- } \\
\text { kolin }\end{array}$ & - & 7 \\
\hline 7 & $\begin{array}{l}\text { Continental } \\
\mathrm{AG}\end{array}$ & $\mathrm{K}$ & 24.08 .2004 & 6000 & $\begin{array}{l}\text { H.-J. Ni- } \\
\text { kolin }\end{array}$ & $>10$ Jahre & - \\
\hline 8 & $\begin{array}{l}\text { Continental } \\
\text { AG }\end{array}$ & $\mathrm{TV}$ & 03.08 .2005 & 6000 & $\begin{array}{l}\text { H.-J. Ni- } \\
\text { kolin }\end{array}$ & 632 & 2 \\
\hline 9 & $\begin{array}{l}\text { Continental } \\
\text { AG }\end{array}$ & $\mathrm{TV}$ & 03.08 .2005 & 10.500 & $\begin{array}{l}\text { H.-J. Ni- } \\
\text { kolin }\end{array}$ & 632 & 3 \\
\hline 10 & $\begin{array}{l}\text { Continental } \\
\mathrm{AG}\end{array}$ & $\mathrm{V}$ & 03.08 .2005 & 16.500 & $\begin{array}{l}\text { H.-J. Ni- } \\
\text { kolin }\end{array}$ & Aufgesplittet & - \\
\hline 11 & $\begin{array}{l}\text { Continental } \\
\mathrm{AG}\end{array}$ & $\mathrm{TV}$ & 04.08 .2006 & 1500 & $\begin{array}{l}\text { H.-J. Ni- } \\
\text { kolin }\end{array}$ & 998 & 4 \\
\hline 12 & $\begin{array}{l}\text { Continental } \\
\text { AG }\end{array}$ & $\mathrm{TV}$ & 04.08 .2006 & 6920 & $\begin{array}{l}\text { H.-J. Ni- } \\
\text { kolin }\end{array}$ & 998 & 5 \\
\hline 13 & $\begin{array}{l}\text { Continental } \\
\text { AG }\end{array}$ & V & 04.08 .2006 & 8420 & $\begin{array}{l}\text { H.-J. Ni- } \\
\text { kolin }\end{array}$ & Aufgesplittet & - \\
\hline 14 & $\begin{array}{l}\text { Continental } \\
\text { AG }\end{array}$ & $\mathrm{TV}$ & 02.08 .2007 & 11.080 & $\begin{array}{l}\text { H.-J. Ni- } \\
\text { kolin }\end{array}$ & 1361 & 6 \\
\hline 15 & $\begin{array}{l}\text { Continental } \\
\text { AG }\end{array}$ & TV & 02.08 .2007 & 920 & $\begin{array}{l}\text { H.-J. Ni- } \\
\text { kolin }\end{array}$ & 1073 & 7 \\
\hline 16 & $\begin{array}{l}\text { Continental } \\
\mathrm{AG}\end{array}$ & V & 02.08 .2007 & 12.000 & $\begin{array}{l}\text { H.-J. Ni- } \\
\text { kolin }\end{array}$ & Aufgesplittet & - \\
\hline 17 & $\begin{array}{l}\text { Continental } \\
\text { AG }\end{array}$ & K & 25.01 .2010 & 134 & $\begin{array}{l}\text { H.-J. Ni- } \\
\text { kolin }\end{array}$ & $>4$ Jahre & - \\
\hline
\end{tabular}


Im vorliegenden Beispiel können aus den 17 verfügbaren Meldungen insgesamt sieben Insidergeschäfte identifiziert werden. Im Falle der Meldungen 1 und 2 ist eine direkte Identifikation des Insidergeschäftes möglich, da sich die Stückzahlen von Kauf und Verkauf decken. Die Haltedauer (hier: 0 Tage) sowie der aus dem Geschäft resultierende Veräußerungsgewinn oder -verlust (hier aus Gründen der Übersichtlichkeit nicht angeführt) können damit direkt berechnet werden.

Abweichend von diesem Idealfall sind zwei weitere Konstellationen möglich:

\section{Kaufmeldung, der keine Verkaufsmeldung zugeordnet werden kann}

Dieser Fall wird im Beispiel durch die Meldungen 7 und 17 (Kauf vom 24.08.2004 und 25.01.2010) repräsentiert. Dem gemeldeten Kauf steht kein nachfolgender Verkauf gegenüber, weshalb in diesem Fall nur eine Untergrenze für die Haltedauer angegeben werden kann. In Bezug auf den Endzeitpunkt der Untersuchung (30.06.2014) ist in diesem Beispiel von einer Mindesthaltedauer von mehr als 10 bzw 4 Jahren auszugehen.

\section{Verkaufsmeldung, der mehrere Kaufmeldungen zugeordnet werden können}

Wenn die Stückzahl eines Kaufs nicht die gesamte Stückzahl des Verkaufs abdeckt, wird dem Verkauf ein weiterer Kauf zugeordnet. Um eine Durchschnittsbildung zu vermeiden, wird der Verkauf in diesem Fall in mehrere Teilverkäufe aufgesplittet und es werden zwei Haltedauern berechnet. Im Beispiel wird dieser Fall durch Meldung 10, 13 und 16 (Verkauf am 03.08.2005, 04.08.2006 und 02.08.2007) repräsentiert. Der Verkauf am 02.08.2007 in Höhe von 12.000 Stück wird beispielsweise in zwei Teilverkäufe zu 11.080 und 920 Stück aufgeteilt, von denen einer dem Kauf am 10.11.2003 und einer dem Kauf am 24.08.2004 zugeordnet wird. Eine Verkaufsmeldung führt in diesem Fall zur Identifikation von zwei Insidergeschäften mit separaten Haltedauern und Veräußerungsgewinnen bzw -verlusten.

\section{Literatur}

Alstadsæter, Annette, und Martin Jacob. 2013. Payout Policies of Privately Held Firms: Flexibility and the Role of Income Taxes. arqus-Working Paper Nr. 152. Berlin: arqus - Arbeitskreis Quantitative Steuerlehre.

Alstadsæter, Annette, und Jacob Martin. 2015. Dividend taxes and income shifting. Scandinavian Journal of Economics doi:10.1111/sjoe.12148.

Ayers, Benjamin, Oliver Zhen Li, und John Robinson. 2008. Tax-Induced Trading Around the Taxpayer Relief Act of 1997. Journal of the American Taxation Association 30:77-100.

Betzer, André, und Erik Theissen. 2009. Insider Trading and Corporate Governance: The Case of Germany. European Financial Management 15:402-429.

Blaufus, Kay, Jonathan Bob, Jochen Hundsdoerfer, Christian Sielaff, Dirk Kiesewetter, und Joachim Weimann. 2015. Perception of Income Tax Rates: Evidence from Germany. European Journal of Law and Economics 40:457-478.

Blouin, Jennifer, Jana S. Raedy, und Douglas Shackelford. 2002. Equity Price Pressure from the 1998 Reduction in the Capital Gains Holding Period. Journal of the American Taxation Association 24:70-93.

Bundesanstalt für Finanzdienstleistungsaufsicht. 2013. Emittentenleitfaden. http://www. bafin.de/SharedDocs/Downloads/DE/Leitfaden/WA/dl_emittentenleitfaden_2013.pdf?_. blob=publicationFile\&v=13. Zugegriffen: 30. Juni 2015.

von Butlar, Julia. 2003. Director's Dealings: Änderungsbedarf aufgrund der Marktmissbrauchsrichtlinie. Betriebs-Berater 41:2133-2139. 
Cook, Eric W., und John F. O’Hare. 1992. Capital Gains Redux: Why Holding Periods Matter. National Tax Journal 45:53-76.

Dai, Zhonglan, Edward Maydew, Douglas Shackelford, und Harold Zhang. 2008. Capital Gains Taxes and Asset Prices: Capitalization or Lock-in? Journal of Finance 63:709-742.

Dardas, Kaspar, und Andre Güttler. 2011. Are Directors' Dealings Informative? Evidence from European Stock Markets. Financial Markets and Portfolio Management 25:111-148.

Deutscher Bundestag. 2007. 16. Wahlperiode, Drucksache 16/5377. http://dipbt.bundestag.de/dip21/btd/ 16/053/1605377.pdf. Zugegriffen: 30. Juni 2015.

Dymke, Björn M., und Andreas Walter. 2008. Insider Trading in Germany - Do Corporate Insiders Exploit Inside Information. Business Research 1:188-205.

Eichfelder, Sebastian, und Mona Lau. 2014. Capital Gains Taxes and Asset Prices: The Impact of Tax Awareness and Procrastination. arqus-Working Paper No. 170. Berlin: arqus - Arbeitskreis Quantitative Steuerlehre.

Ferris, Stephen P., Robert A. Haugen, und Anil K. Makhija. 1987. Predicting Contemporary Volume with Historic Volume at Differential Price Levels: Evidence Supporting the Disposition Effect. Journal of Finance 43:677-697.

Fidrmuc, Jana P., Marc Goergen, und Luc Renneboog. 2006. Insider Trading, News Releases and Ownership Concentration. Journal of Finance 61:2931-2973.

Hanlon, Dean, und Sean Pinder. 2007. An Empirical Investigation of whether Australian Capital Gains Tax Reforms Influence Individual Investor Behaviour. Pacific-Basin Finance Journal 5:481-493.

Holt, Charles, und John Shelton. 1961. The Implications of the Capital Gains Tax for Investment Decisions. Journal of Finance 16:559-580.

Jacob, Martin. 2013. Capital Gains Taxes and the Realization of Capital Gains and Losses - Evidence from German Income Tax Data. FinanzArchiv 69:30-56.

Landsman, Wayne, und Douglas Shackelford. 1995. The Lock-In Effect of Capital Gains Taxes: Evidence from the RJR Nabisco Leveraged Buyout. National Tax Journal 48:245-259.

Lang, Mark, und Douglas Shackelford. 2000. Capitalization of Capital Gains Taxes: Evidence from Stock Price Reactions to the 1997 Rate Reduction. Journal of Public Economics 76:69-85.

Liang, Jia-Wen, Steven R. Matsunaga, und Dale C. Morse. 2002. The Effect of the Expected Holding Period on the Market Reaction to a Decline in the Capital Gains Tax Rate. Journal of the American Taxation Association 24(Supplement):49-64.

Lin, Ji.-Chai., und John S. Howe. 1990. Insider Trading in the OTC Market. Journal of Finance 45:1273-1284.

Niemann, Rainer, und Caren Sureth. 2013. Sooner or Later? - Paradoxical Investment Effects of Capital Gains Taxation under Simultaneous Investment and Abandonment Flexibility. European Accounting Review 22:367-390.

Odean, Terrance. 1998. Are Investors Reluctant to Realize their Losses? Journal of Finance 53:1775-1798.

Osterloh, Falk. 2007. Directors' Dealings - \$15a WpHG im Vergleich mit den Regelungen in den Vereinigten Staaten von Amerika, Großbritannien sowie der europäischen Marktmissbrauchsrichtlinie unter besonderer Berücksichtigung des persönlichen Anwendungsbereichs. Berlin: Duncker \& Humblot.

Pluskat, und Sorika. 2005. Die Neuregelungen des Director's Dealings in der Fassung des Anlegerschutzverbesserungsgesetzes. Der Betrieb 58:1097-1101.

Rau, Michael. 2004. Directors' Dealings am deutschen Aktienmarkt: Empirische Analyse meldepflichtiger Wertpapiergeschäfte. Dissertation. Zürich: Universität Zürich.

Reese, William. 1998. Capital Gains Taxation and Stock Market Activity. Journal of Finance 53:1799-1819.

Seyhun, Hasan Nejat. 1986. Insiders' Profits, Costs of Trading, and Market Efficiency. Journal of Financial Economics 16:189-212.

Shefrin, Hersh, und Meir Statman. 1985. The Disposition to Sell Winners too Early and Ride Losers too Long: Theory and Evidence. Journal of Finance 40:777-790.

Sprinkel, Beryl, und Kenneth West. 1962. Effects of Capital Gains Taxes on Investment Decisions. Journal of Business 35:122-134.

Watrin, Christoph, und Hanno Benhof. 2009. Zum Lock-in-Effekt einer Besteuerung von Veräußerungsgewinnen. Eine empirische Untersuchung am Beispiel neu emittierter Aktien. Steuer und Wirtschaft $86: 300-310$.

Weiler, Lothar, und Oliver Tollkühn. 2002. Die Neuregelungen des Director's Dealing nach dem Vierten Finanzmarktförderungsgesetz. Der Betrieb 55:1923-1927. 